\title{
Studying Scale Dependency of Aerosol-Cloud Interactions Using Multiscale Cloud Formulations $\mathfrak{A}$
}

\author{
Timothy Glotfelty, ${ }^{\mathrm{a}}$ Kiran Alapaty, ${ }^{\mathrm{b}}$ Jian He, ${ }^{\mathrm{c}}$ Patrick Hawbecker,${ }^{\mathrm{d}}$ Xiaoliang Song, ${ }^{\mathrm{e}}$ \\ AND GUANG ZHANG ${ }^{\mathrm{e}}$

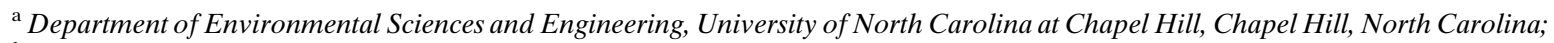 \\ ${ }^{\mathrm{b}}$ Center for Environmental Measurements and Modeling, U.S. Environmental Protection Agency, Research Triangle Park, North \\ Carolina; ${ }^{\mathrm{c}}$ Program in Atmospheric and Oceanic Sciences, Princeton University, Princeton, New Jersey; ${ }^{\mathrm{d}}$ Department of Marine, \\ Earth, and Atmospheric Sciences, North Carolina State University, Raleigh, North Carolina; ${ }^{\mathrm{e}}$ Scripps Institution of Oceanography, \\ University of California, San Diego, La Jolla, California
}

(Manuscript received 26 July 2019, in final form 4 August 2020)

\begin{abstract}
The Weather Research and Forecasting Model with Aerosol-Cloud Interactions (WRF-ACI) configuration is used to investigate the scale dependency of aerosol-cloud interactions (ACI) across the "gray zone" scales for grid-scale and subgrid-scale clouds. The impacts of ACI on weather are examined across regions in the eastern and western United States at 36,12,4, and $1 \mathrm{~km}$ grid spacing for short-term periods during the summer of 2006. ACI impacts are determined by comparing simulations with current climatological aerosol levels to simulations with aerosol levels reduced by $90 \%$. The aerosol-cloud lifetime effect is found to be the dominant process leading to suppressed precipitation in regions of the eastern United States, while regions in the western United States experience offsetting impacts on precipitation from the cloud lifetime effect and other effects that enhance precipitation. Generally, the cloud lifetime effect weakens with decreasing grid spacing due to a decrease in relative importance of autoconversion compared to accretion. Subgrid-scale ACI are dominant at $36 \mathrm{~km}$, while grid-scale ACI are dominant at 4 and $1 \mathrm{~km}$. At $12 \mathrm{~km}$ grid spacing, grid-scale and subgridscale ACI processes are comparable in magnitude and spatial coverage, but random perturbations in grid-scale ACI impacts make the overall grid-scale ACI impact appear muted. This competing behavior of grid- and subgrid-scale clouds complicate the understanding of ACI at $12 \mathrm{~km}$ within the current WRF modeling framework. The work implies including subgrid-scale cloud microphysics and ice/mixed-phase-cloud ACI processes may be necessary in weather and climate models to study ACI effectively.
\end{abstract}

KEYWORDS: Cloud parameterizations; Clouds; Convective parameterization; Cumulus clouds; Model evaluation/performance

\section{Introduction}

The scientific communities' understanding of aerosol-cloud interactions (ACI) remains incomplete (e.g., Denman et al. 2007; Boucher et al. 2013), either from modeling perspectives or measurements analyses (e.g., Wall et al. 2013; Ghan et al. 2016). Models have been shown to reasonably capture some of the complex processes involved in simulating ACI, but many errors and uncertainties exist (e.g., Wyant et al. 2015). Understanding of ACI is important (Fan et al. 2016) to the study of aerosol-climate interactions, especially since the impact of aerosol indirect effects on precipitation can be larger than the impact from aerosol direct or semi-indirect effects (e.g., Kushta et al. 2014).

ACI variability in models arises from the use of differing aerosol activation parameterizations (e.g., Tonttila et al. 2015; Wilcox et al. 2015), cloud microphysical schemes (e.g., Jones et al. 2001; Menon and Rotstayn 2006; Wilcox et al. 2015), and choice of cloud drop to raindrop autoconversion parameterization (e.g., Penner et al. 2006; Tonttila et al. 2015; Xie and Liu, 2015; White et al. 2017). Model representations of ice nucleation

Supplemental information related to this paper is available at the Journals Online website: https://doi.org/10.1175/JAS-D-190203.s1.

Corresponding author: Kiran Alapaty, alapaty.kiran@epa.gov that include aerosols are a large source of uncertainty, these processes are treated in some modeling systems (e.g., Saleeby and van den Heever 2013; Thompson and Eidhammer 2014), but are generally overlooked by many models that include ACI (e.g., Quaas et al. 2009; Zelinka et al. 2014). Another area of uncertainty is the role of aerosols on cumulus clouds, which is often not treated by weather and climate models (e.g., Menon and Rotstayn 2006). ACI impacts on convective clouds have been shown to be as significant as variations in the convective environment (e.g., Storer et al. 2010) and a limitation that complicates the study of ACI scale dependency (e.g., Archer-Nicholls et al. 2016).

In recent years, studies have focused on the scale dependency of ACI (e.g., Chen et al. 2015; Ma et al. 2015; ArcherNicholls et al. 2016; Possner et al. 2016). Chen et al. (2015) found evidence of inherent scale dependency of ACI on stratocumulus clouds due to suppression of spatial variability at coarse resolutions. The global simulations of Ma et al. (2015) showed a reduction in the impact of ACI with increasing horizontal resolution due to a relative increase in the importance of accretion compared to autoconversion. Ma et al. (2015) also found some enhancement in aerosol effects as pollutant emissions become more concentrated at higher resolutions. A modeling work of Possner et al. (2016) showed that ACI in stratocumulus ship tracks were scale dependent due to differences in vertical mixing between fine and coarse resolutions. In another study, Archer-Nicholls et al. (2016) showed that 
aerosol semidirect effects were far more sensitive to resolution than aerosol indirect effects, but the authors noted that their simulation results were only representative of the tropical convection case they have studied. That study may also be limited by neglecting the impact of ACI on the cumulus parameterization and neglecting the impact of ice nucleating particles. These modeling studies provided a glimpse into the resolution dependency of ACI, but much work remains to be done.

Recently, Glotfelty et al. (2019) have developed the Weather Research and Forecasting Model with AerosolCloud Interactions (WRF-ACI) system, and evaluated the seasonal impacts of aerosols for the eastern U.S. region using $12 \mathrm{~km}$ grid spacing. Results indicated a strong cloud lifetime effect from current climatological aerosols, which increase domain average cloud liquid water path and reduce domain average precipitation as compared to a simulation with aerosols reduced by $90 \%$. Increased cloud-top heights indicated a thermodynamic invigoration effect, but the impact of thermodynamic invigoration on precipitation was overwhelmed by the cloud life time effect. A combination of cloud lifetime and cloud albedo effects increased domain average shortwave cloud forcing by $\sim 3.0 \mathrm{Wm}^{-2}$. Subgrid-scale clouds experienced a stronger response to aerosol levels, while grid-scale clouds were subjected to thermodynamic feedbacks because of the design of the WRF modeling framework. The muted impact of ACI on grid-scale clouds shown in that study did not necessarily suggested that grid-scale clouds have weaker ACI compared to subgrid-scale clouds. Rather, the findings of that study suggested that grid-scale ACI can become overwhelmed by the competition between the grid-scale and subgrid-scale parameterizations at $12 \mathrm{~km}$ grid spacing. This result has led to the question of whether ACI impacts vary across spatial scales, including "gray zone" scales.

In this study, the same WRF-ACI modeling system (Glotfelty et al.2019) is employed in order to study the scale dependency of ACI over the continental United States. Simulations are conducted across the "gray zone" or convection-permitting scales (i.e., 1-12 km grid spacing) (e.g., Hong and Dudhia 2012) and at a traditional mesoscale grid spacing $(36 \mathrm{~km})$. These simulations use a scale-aware cumulus convection parameterization scheme that includes a double-moment convective cloud microphysics parameterization. The uniqueness of the study is that it advances ACI science by overcoming some of the limitations of both Ma et al. (2015) and Archer-Nicholls et al. (2016). This is done by simulating liquid and solid phase ACI in both grid-scale and subgrid-scale clouds, at relatively high spatial resolutions. Thus, the specific objectives of this study are to 1) determine if ACI are scale dependent in the WRF-ACI framework for numerical weather simulation scenarios and 2) investigate potential factors that contribute to the scale dependency of ACI.

\section{Methodology}

\section{a. The WRF-ACI model}

The WRF-ACI model, WRFV3.81 (Glotfelty et al. 2019), is a new configuration of the Weather Research and Forecasting Model (Skamarock and Klemp 2008) that contains a number of ACI processes not present in many weather and climate models. Four distinctive components of the WRF-ACI system include
1) the multiscale Kain-Fritsch (MSKF) cumulus convection parameterization scheme (Glotfelty et al. 2019; He and Alapaty 2018; Alapaty et al. 2014; Mahoney 2016; Zheng et al. 2016), with an updated version of the subgrid-scale convective cloud microphysics parameterization based on Song and Zhang (2011); 2) consistent aerosol activation and ice nucleation parameterizations in both the grid-scale and subgrid-scale cloud microphysics parameterizations, based on Abdul-Razzak and Ghan (2000) and Liu and Penner (2005), respectively; 3) a temporally and spatially varying bias-corrected prescribed aerosol climatology; and 4) full coupling of the grid-scale and subgrid-scale cloud microphysics parameterizations to the Rapid Radiative Transfer Model for GCMs (RRTMG) radiation parameterization, for the simulation of aerosol indirect effects.

In WRF-ACI, aerosols are prescribed as the 10 -yr average (i.e., 2001-10) from the global climate simulations of Glotfelty et al. (2017), which have been bias corrected by multiplying the aerosol concentration by the mean bias against U.S. observations. Cloud droplet activation and ice nucleation of these aerosols are conducted using the Abdul-Razzak and Ghan (2000) and Liu and Penner (2005) parameterizations, respectively, in MSKF. These parameterizations also replace the Cooper (1986) ice nucleation scheme and the prescribed cloud droplet number concentration (e.g., $250 \mathrm{~cm}^{-3}$ ) in the Morrison double-moment (MDM) microphysics scheme for consistency. MSKF's scale dependent formulations have been updated to include the double-moment microphysics scheme of Song and Zhang (2011), which simulates autoconversion, accretion, collection, cloud droplet activation, freezing, the BergeronFindeisen process (Wegener 1911; Bergeron 1935; Findeisen 1938), ice nucleation, and convective detrainment of hydrometeors. The partitioning between cloud ice and liquid water has also been updated to account for the presence of supercooled water using the formulation of $\mathrm{Hu}$ et al. (2010). The cloud droplet mixing ratio, ice crystal mixing ratio, snow mixing ratio, and effective radii from both MSKF and MDM are then passed to the RRTMG long and shortwave radiation schemes to simulate radiative feedbacks. At this time, WRFACI only simulates aerosol indirect effects and the aerosol climatology has not been coupled to the RRTMG scheme. Thus, aerosol direct effects are not included in the current version of the WRF-ACI modeling system. For greater details on WRF-ACI treatments and how WRF-ACI compares to other scale and aerosol-aware schemes, readers are referred to Glotfelty et al. (2019). Greater details of the MSKF scheme can also be found in the online supplementary material text S1.

This modeling system allows for the simulation of ACI without incurring the huge computational costs and complexity of meteorology and chemistry coupled models. While it advances the science of the WRF modeling system, it comes with a simplified representation of aerosol loading in the atmosphere. The entire model configuration listing the various physics options used is shown in Table 1.

\section{b. Numerical simulations}

To investigate the scale dependency of ACI, several WRFACI simulations were conducted at various horizontal resolutions for two short-term periods (5-7 days). These time periods, 
TABLE 1. Model configurations. Acronyms: Flux-adjusting surface data assimilation system (FASDAS); four-dimensional data assimilation (FDDA); Morrison double moment (MDM); multiscale Kain-Fritsch (MSKF); NOAA/NCEP-Oregon State University-Air Force Research Laboratory-NOAA/Office of Hydrology land surface model (Noah); Rapid Radiative Transfer Model for GCMs (RRTMG); Yonsei University (YSU).

\begin{tabular}{ll}
\hline \multicolumn{1}{c}{ Parameterization } & \multicolumn{1}{c}{ Configuration } \\
\hline Cumulus & MSKF (Alapaty et al. 2014; Zheng et al. 2016) \\
Microphysics & MDM (Morrison et al. 2005, 2009) \\
Boundary layer & YSU (Hong et al. 2006) \\
Surface layer & Monin-Obukhov (Monin and Obukhov 1954; Janjić 2002) \\
Land surface model & Noah (Chen and Dudhia 2001; Ek et al. 2003) \\
Radiation & RRTMG (Clough et al. 2005; Iacono et al. 2008) \\
Free-atmosphere data assimilation & FDDA (Stauffer and Seaman 1990; Stauffer and Seaman 1994) \\
Surface data assimilation & FASDAS (Alapaty et al. 2008; He et al. 2017) \\
\hline
\end{tabular}

as well as the WRF-ACI domain and horizontal grid spacing information are shown in Table 2. The 17-24 June 2006 time period is selected to investigate ACI scale dependency over the eastern United States, since it represents a period in which precipitation occurred throughout the entire domain of interest. The WRF-ACI domains for this experiment consist of a $36 \mathrm{~km}$ simulation over the continental United States (CONUS), a $12 \mathrm{~km}$ simulation over the eastern United States (EUS), a $4 \mathrm{~km}$ simulation over the Northeast/mid-Atlantic region (NE), a $4 \mathrm{~km}$ simulation over the Southeast (SE), and a $1 \mathrm{~km}$ simulation over northern Mississippi (NMS). All these simulations use one-way nesting interactions following the NDOWN methodology. The spatial coverage of the eastern U.S. domain regions is shown in Figs. S1 and S2 in the online supplemental material. The 23-28 July 2006 time period is selected to investigate ACI scale dependency during the North American Southwest monsoon (NASM). NASM precipitation was present during this time period, with some additional moisture due to the presence of Tropical Storm Emilia off the coast of Mexico. The WRF-ACI domains for this experiment consist of a $36 \mathrm{~km}$ CONUS domain, a $12 \mathrm{~km}$ domain over the western United States (WUS), a $4 \mathrm{~km}$ domain over the Four Corners region (FC), and a $1 \mathrm{~km}$ domain over northern Colorado (NCO). The spatial coverage of the western U.S. domain regions is shown in Figs. S3 and S4.

The eastern U.S. and western U.S. domains are selected because these domains represent both moisture intensive (i.e., the Southeast) and moisture deprived (i.e., Four Corners regions) regimes. The NMS and NCO regions are selected to study ACI at $1 \mathrm{~km}$ grid spacing because these regions were areas within the larger regions of interest with relatively abundant precipitation and cloud coverage; however, this domain selection is somewhat arbitrary. The NE region is included since this region has slightly different meteorological conditions compared to the SE. However, a $1 \mathrm{~km}$ simulation was not conducted in the NE region due to limited computational resources.

Two sets of simulations are conducted for both experiments. The first set of simulations is a standard WRF-ACI simulation with bias-corrected-current-climatology aerosols, hereafter referred to as WACI. The second set of simulations are conducted with all aerosol concentrations (i.e., anthropogenic and natural) reduced by $90 \%$, hereafter referred to as LAERO. Table S1 shows the mapping of aerosols from the global model output files to WRF-ACI. The discussion presented here will focus on the areas covered by both the 4 and $1 \mathrm{~km}$ domains. To facilitate this comparison, output from the 36 and $12 \mathrm{~km}$ domains is regridded to the 4 and $1 \mathrm{~km}$ domains. Similarly, output from the $4 \mathrm{~km}$ domains is regridded to the $1 \mathrm{~km}$ domains.

Since regional weather simulations drift from actual weather, it is very important to steer the model toward reality so that ACI can be studied accurately. Additionally, it is equally important to ensure that nudging (data assimilation) does not dominate the physical processes represented in a model. Bullock et al. (2014) have extensively studied the optimal nudging parameters for the free atmosphere. Similarly,

TABLE 2. WRF-ACI experiment configurations.

\begin{tabular}{|c|c|c|}
\hline Time period & Domain coverage/name & Horizontal resolution $(\mathrm{km})$ \\
\hline \multirow[t]{5}{*}{ 17-24 Jun 2006} & Continental United States (CONUS) & 36 \\
\hline & Eastern United States (EUS) & 12 \\
\hline & Northeast/mid-Atlantic United States (NE) & 4 \\
\hline & Southeast United States (SE) & 4 \\
\hline & Northern Mississippi (NMS) & 1 \\
\hline \multirow[t]{4}{*}{ 23-28 Jul 2006} & Continental United States (CONUS) & 36 \\
\hline & Western United States (WUS) & 12 \\
\hline & Four Corners region (FC) & 4 \\
\hline & Northern Colorado (NCO) & 1 \\
\hline
\end{tabular}




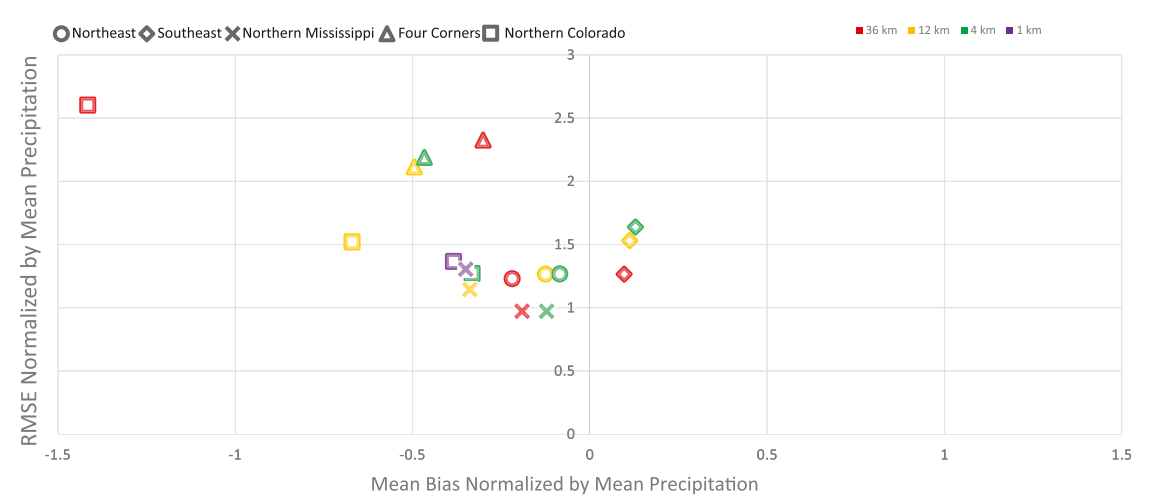

FIG. 1. Domain-wide mean normalized bias vs normalized root-mean-square error for the Northeast (circles), Southeast (diamonds), northern Mississippi (crosses), Four Corners (triangles), and northern Colorado (squares) domains at 36 (red), 12 (gold), 4 (green), and $1 \mathrm{~km}$ (purple) grid spacing.

Alapaty et al. (2008) and He et al. (2017) studied the impact of surface nudging by using a time scale representative of convective boundary layer processes. Thus, the numerical simulations presented in this work use optimal analysis nudging strength to reduce secondary feedbacks, especially when aerosol concentrations are perturbed, to elucidate solely the impact of the aerosol indirect effects. The simulations are nudged in the free atmosphere via four-dimensional data assimilation (FDDA; Stauffer and Seaman 1990, 1994) and the surface using the flux-adjusting surface data assimilation system (FASDAS; Alapaty et al. 2008; He et al. 2017). FASDAS is an analysis nudging system similar to FDDA that corrects errors in surface temperature and moisture fields in a thermodynamically consistent manner. FASDAS consists of direct nudging of temperature and water vapor mixing ratio in the lowest model layer that is balanced by an indirect adjustment of the surface sensible heat flux and latent heat fluxes in the land surface model (Alapaty et al. 2008). More details on FASDAS as implemented in WRF can be found in He et al. (2017). In the free atmosphere with FDDA, the temperature and horizontal wind speed components are nudged using a relaxing coefficient of $5.0 \times 10^{-5} \mathrm{~s}^{-1}$ and the water vapor mixing ratio is nudged with a relaxation coefficient of $5 \times$ $10^{-6} \mathrm{~s}^{-1}$ (Bullock et al. 2014). These weak nudging values are used as they allow for numerical consistency of WRF's physics parameterizations, while still constraining model drift. FASDAS nudges surface temperature and moisture using relaxation coefficients of $8.3 \times 10^{-4} \mathrm{~s}^{-1}$. The FASDAS coefficients are based on the time scale of large-eddy turnover (i.e., $20 \mathrm{~min}$ ) within the boundary layer (Alapaty et al. 2008). No nudging is applied in planetary boundary layer. These nudging strategies were also found to be successful in ACI studies by Glotfelty et al. (2019) in simulating regional climate.

\section{c. Data}

The WRF simulations are initialized using the same data and techniques as Glotfelty et al. (2019). Initial conditions, boundary conditions, and nudging files are obtained from the $12 \mathrm{~km}$ reanalysis of the National Centers for Environmental Prediction
North American Model (NAM), merged with surface and upper air observations by the National Center for Atmospheric Research's (NCAR) OBSGRID utility. These observations include radiosonde measurements, wind profiler measurements, and Weather Surveillance Radar-1988 Doppler (WSR-88D) velocity azimuth display algorithm wind data obtained from NCAR and surface meteorological fields obtained from the Meteorological Assimilation Data Ingest System. Precipitation performance of the WACI simulations are evaluated against NOAA stage-IV precipitation estimates in a similar manner to that in Glotfelty et al. (2019).

\section{Model evaluation}

Since Glotfelty et al. (2019) conducted a detailed evaluation of precipitation, radiation, and cloud properties within WRFACI at $12 \mathrm{~km}$ grid spacing for the full summer 2006 season, the current study exclusively focuses on evaluating the scale dependency of precipitation performance across grid spacings ranging from 36 to $1 \mathrm{~km}$.

\section{Precipitation evaluation}

Domain-wide mean bias (MB) and root-mean-square error (RMSE) statistics derived from stage-IV precipitation estimates that have been normalized by mean simulated precipitation are plotted in Fig. 1 for each of the aforementioned domains at each grid spacing. The MB and RMSE are normalized in this manner to make the eastern U.S. and western U.S. statistics comparable despite large differences in precipitation magnitude between these two regions (see Fig. S5 as an example). In this figure, points closest to the figure's origin indicate excellent model performance and points farthest away indicate poor performance. In general, WRF-ACI has a better representation of precipitation over regions in the eastern United States compared to regions in the western United States. However, it should be noted that stage-IV precipitation estimates are more uncertain in the western United States due to sparse radar coverage, blockage from the mountainous terrain, and uncertainties in the rain fall processing algorithm (Nelson et al. 2016). The Southeast experiences an increase in RMSE with decreased grid spacing, while the Northeast region 


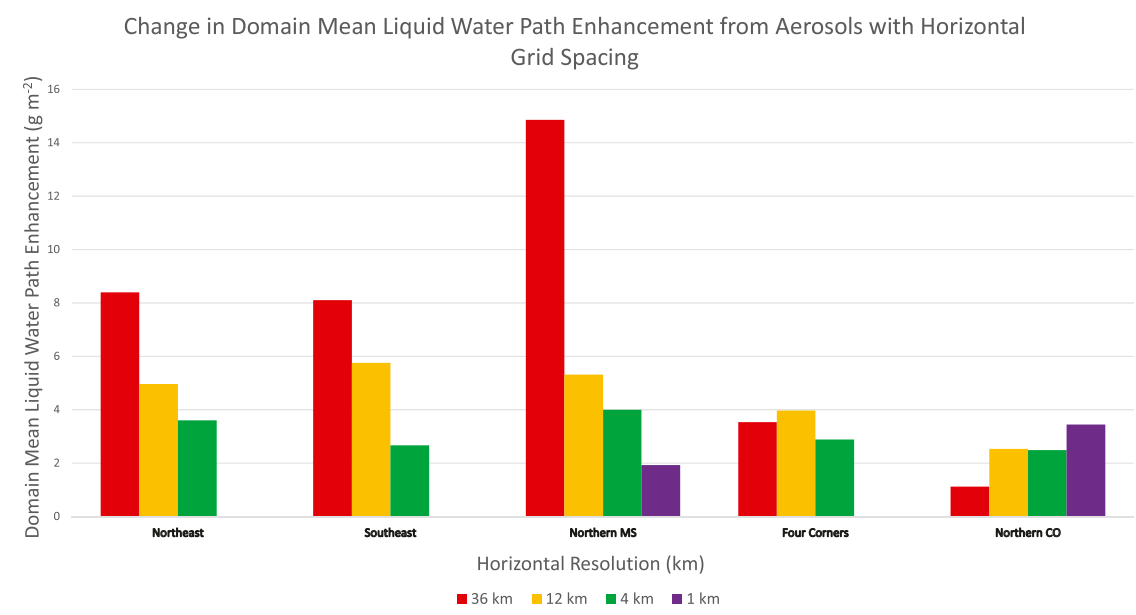

FIG. 2. The domain-wide mean change in cloud liquid water path $\left(\mathrm{g} \mathrm{m}^{-2}\right)$ between the WACI and LAERO simulations for the Northeast (NE), Southeast (SE), northern Mississippi (NMS), Four Corners (FC), and northern Colorado (NCO) domains at 36 (red), 12 (gold), 4 (green), and $1 \mathrm{~km}$ (purple) grid spacing.

experiences relatively consistent performance across scales. The increase in RMSE with increased grid spacing in the Southeast is likely the result of enhanced spatial variability in convective precipitation at finer resolution, leading to larger timing and location errors for precipitation. The NMS domain experiences nonmonotonic fluctuations in model performance across scales, likely due fluctuations in timing and location errors over this domain's relatively small spatial extent. RMSE improves significantly in the FC and NCO domains from 36 to $12 \mathrm{~km}$ grid spacing, since the terrain and other meteorological parameters are better resolved leading to better resolved precipitation. However, enhanced grid spacing does not significantly improve model performance at finer resolutions (i.e., 4 and $1 \mathrm{~km}$ grid spacing) in these regions. Precipitation performance (e.g., MB and RMSE) is maximized at $4 \mathrm{~km}$ grid spacing in all regions except the Southeast. However, this may not be a generally applicable result, as the stage-IV dataset is prepared at $4 \mathrm{~km}$ resolution and thus may be subject to less distortion when compared to $4 \mathrm{~km}$ simulated fields. These results are consistent with previous studies that show increases in simulated errors with decreased grid spacing, when the grid spacing is reduced below $\sim 10 \mathrm{~km}$ (e.g., Mass et al. 2002; Li et al. 2014).

\section{Scale dependency of aerosol-cloud interactions}

\section{a. Scale dependency of aerosol-cloud interaction impacts on cloud liquid water}

The domain-wide mean changes in cloud liquid water path (LWP) between the WACI and LAERO simulations for the NE, SE, NMS, FC, and NCO regions at 36, 12, 4, and $1 \mathrm{~km}$ grid spacing are shown in Fig. 2. It is important to note again that only the NMS and NCO regions have $1 \mathrm{~km}$ simulations. In all analyzed regions and at each grid spacing, the domain mean ACI impact on LWP is an increase of various magnitudes. This is consistent with the cloud-lifetime effect, wherein an increase in aerosol levels leads to reduction in precipitation efficiency and a subsequent increase in LWP (e.g., Albrecht 1989). In general, the eastern U.S. regions experience a greater LWP enhancement compared to regions in the western United States at 36 and $12 \mathrm{~km}$ grid spacing, potentially indicating that LWP-ACI impacts are more relevant in moisture intensive regimes. In the eastern United States, there is also a clear trend for the reduction in the LWP enhancements with decreasing grid spacing in the NE, SE, and NMS regions. The trend in LWP enhancements in the western United States is less straightforward, with a fairly constant LWP enhancement over the $\mathrm{FC}$ region at each grid spacing and a small increasing trend with reduced grid spacing in NCO. The variations in the trends of LWP in the western United States could result from multiple factors, including but not limited to 1) the presence of more mixed phase clouds in the mountainous portions of the western United States, 2) less available moisture for cloud formation, 3 ) the lower aerosol loadings and differing speciation in the WUS compared to the EUS, 4) uncertainty in the ability of the model to resolve cloud formation at the coarser grid spacing due to the complex terrain in the FC and NCO domains, and 5) limitations in WRF-ACI parameterizations.

For a more detailed analysis of the ACI impacts on LWP in the western and eastern United States, the difference in subgrid-scale, grid-scale, and total LWP between the WACI and LAERO simulations (i.e., WACI - LAERO) at 36, 12, and $4 \mathrm{~km}$ grid spacing over the FC and SE regions are shown in Figs. 3 and 4, respectively. In the FC region (Fig. 3), subgridscale cloud-lifetime effects dominate the total impact on LWP at 36 and $12 \mathrm{~km}$ grid spacing. At $4 \mathrm{~km}$ grid spacing, subgridscale clouds are less prominent causing further reductions in LWP differences. The opposite signature in grid-scale LWP differences at 36 and $12 \mathrm{~km}$ occur from reduced condensation (see LWP source panels in Fig. S6), which likely results from reductions in moisture availability due to competition with the subgrid-scale clouds. At $4 \mathrm{~km}$ grid spacing, there is less competition with subgrid-scale clouds allowing for a domain average increase in grid-scale LWP (e.g., $1.6 \mathrm{~g} \mathrm{~m}^{-2}$ ). This is in 
Subgrid Scale
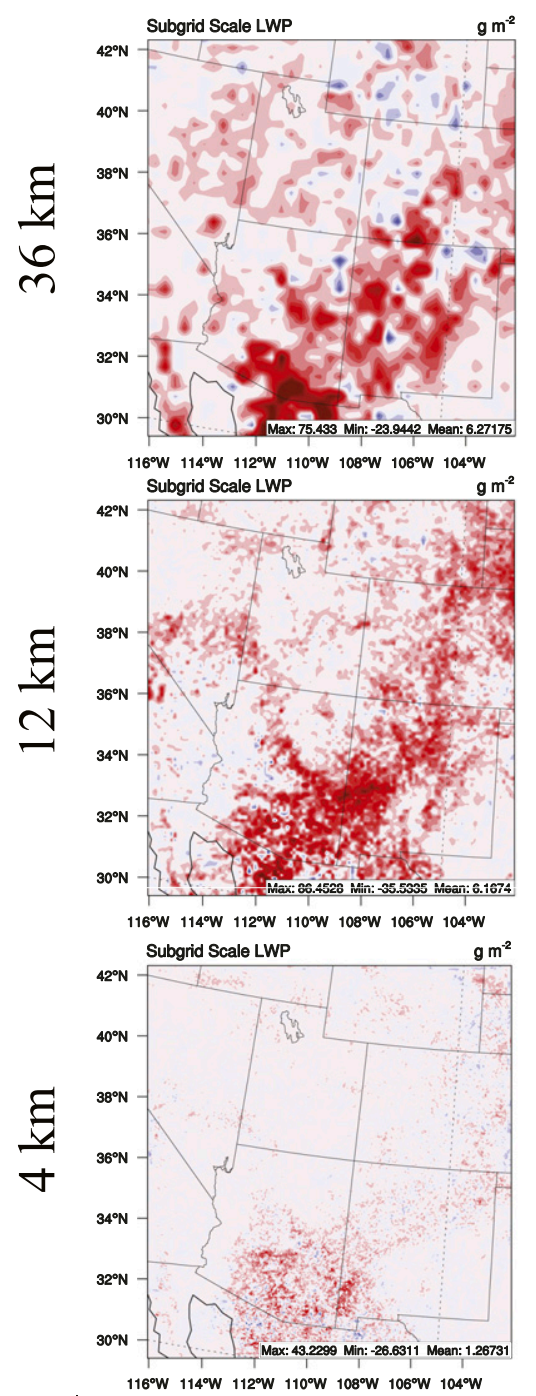

Grid Scale
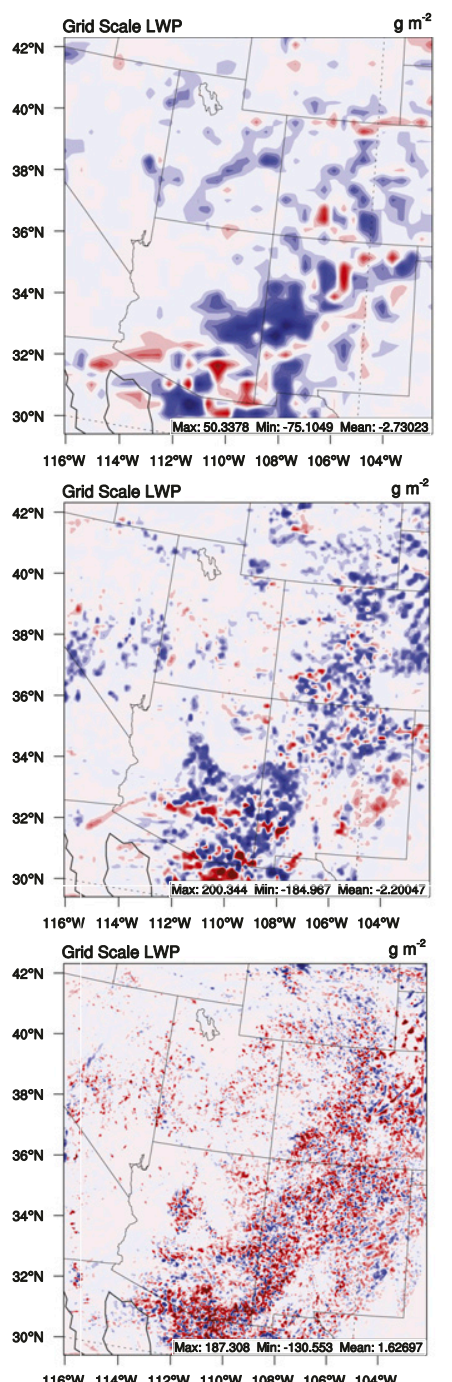

Total

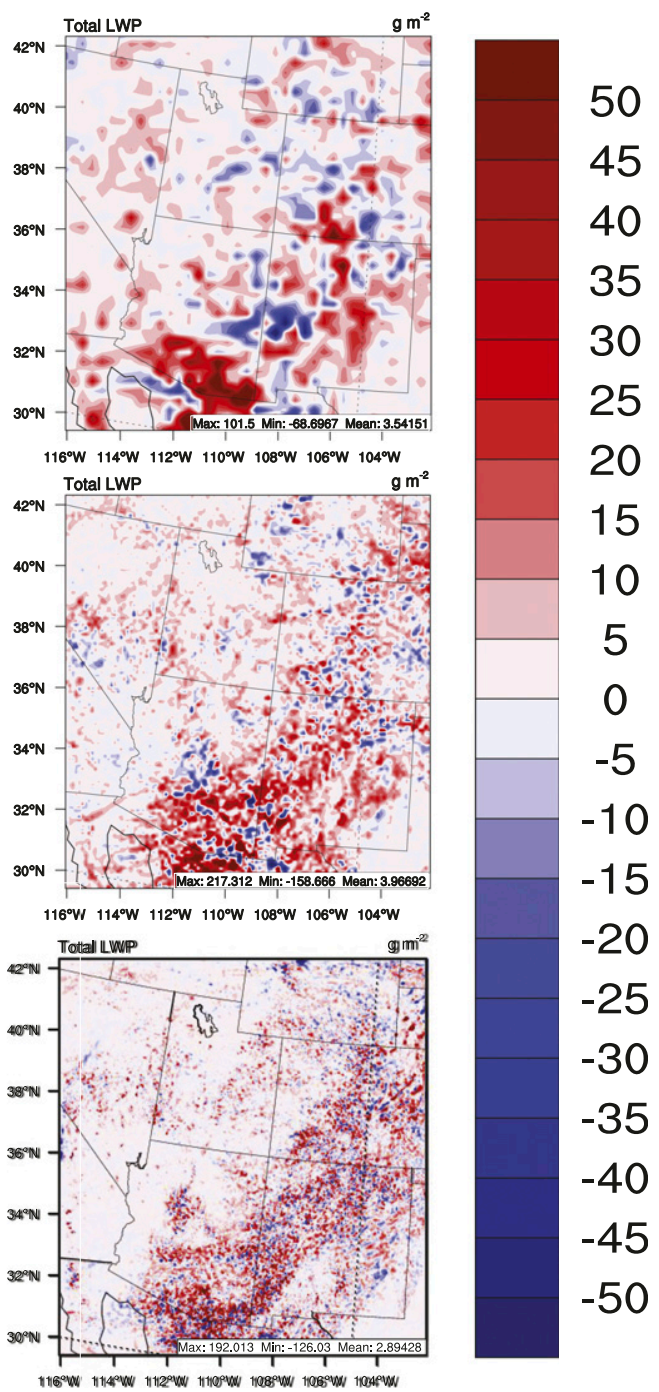

FIG. 3. The difference in (left) subgrid-scale, (center) grid-scale, and (right) total cloud liquid water path ( $\mathrm{g} \mathrm{m}^{-2}$ ) between the WACI and LAERO simulations over the FC region at (top) 36 , (middle) 12 , and (bottom) $4 \mathrm{~km}$.

response to the cloud-lifetime effect that is greater in magnitude compared to the subgrid scale LWP enhancement (e.g., $\sim 1.3 \mathrm{~g} \mathrm{~m}^{-2}$ ). The total LWP differences across all grid spacings indicate a net increase in LWP consistent with that shown in the Fig. 2.

In the SE region (Fig. 4), ACI impacts on LWP are similar to the $\mathrm{FC}$ region at $36 \mathrm{~km}$ grid spacing, with a dominant subgridscale LWP enhancement and a domain-wide mean reduction in grid-scale LWP. At $12 \mathrm{~km}$ grid spacing, both subgrid-scale and grid-scale clouds experience enhancements in LWP from the cloud-lifetime effect, but the subgrid-scale LWP enhancement is still larger (e.g., $\sim 3.7 \mathrm{~g} \mathrm{~m}^{-2}$ ) compared to the grid-scale LWP enhancement (e.g., $\sim 2.1 \mathrm{~g} \mathrm{~m}^{-2}$ ). At $4 \mathrm{~km}$ grid spacing, only small-scale clouds are represented by the subgrid-scale parameterization, resulting in larger grid-scale LWP enhancements (e.g., $1.6 \mathrm{~g} \mathrm{~m}^{-2}$ ) compared to the subgrid-scale LWP enhancements (e.g., $\sim 1.1 \mathrm{~g} \mathrm{~m}^{-2}$ ). The total LWP enhancements decrease with the decrease in grid spacing as shown in Fig. 2.

The differences in grid scale ACI impacts at $12 \mathrm{~km}$ grid spacing between the $\mathrm{FC}$ and $\mathrm{SE}$ regions are the most striking. One possibility for this difference is the moisture regime. The significant moisture availability of the SE region should reduce the effect of competition for moisture between both the gridscale and subgrid-scale clouds, which would allow for increases in LWP from both cloud types at $12 \mathrm{~km}$ grid spacing. In the FC domain, moisture is limited and as a result the effect of moisture competition would be stronger, inhibiting grid-scale LWP enhancements until subgrid-scale clouds become less relevant at $4 \mathrm{~km}$ grid spacing. It is also possible that at $12 \mathrm{~km}$ grid spacing cloud features in the FC region are better resolved 


\section{Subgrid Scale}
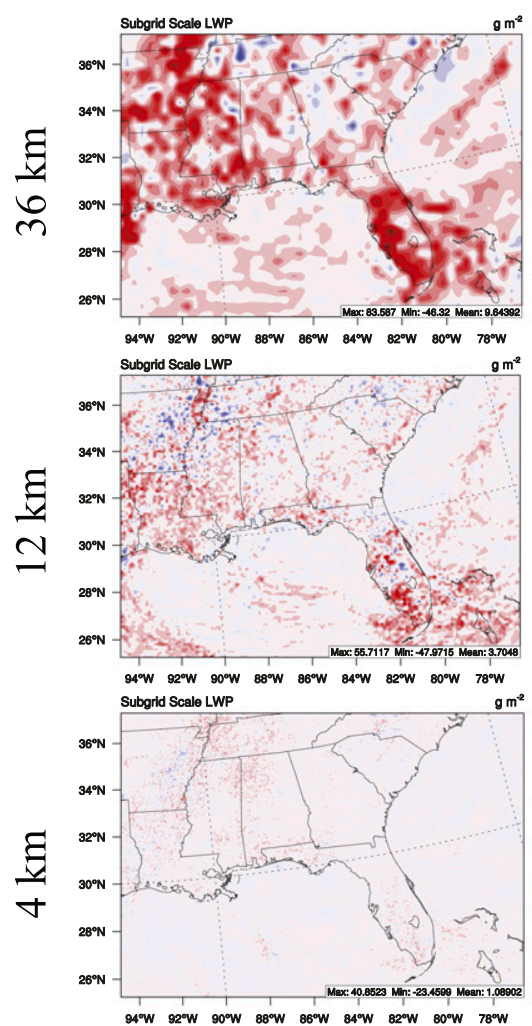

\section{Grid Scale}
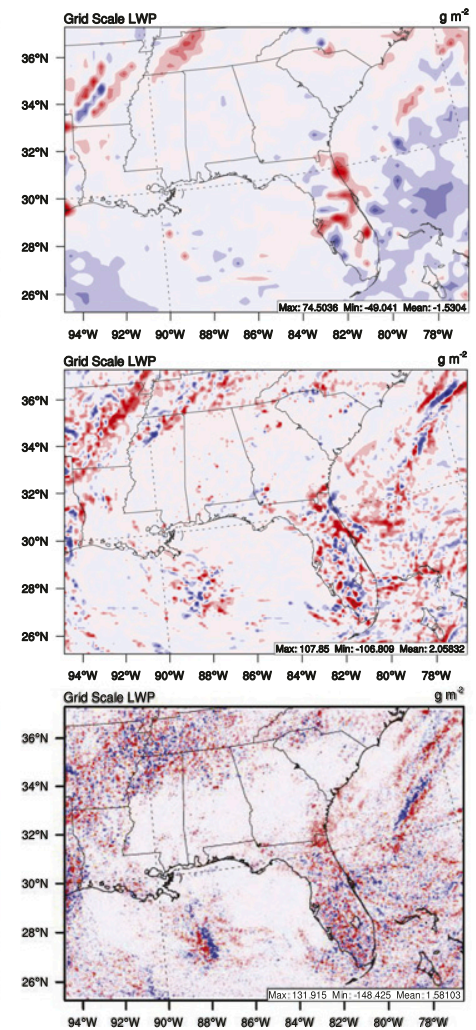

Total

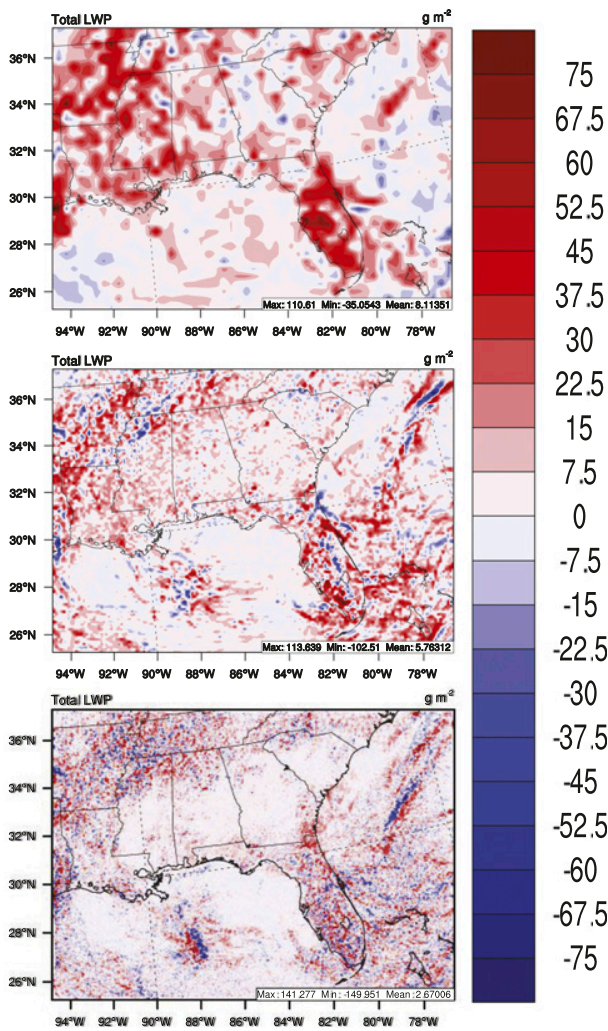

FIG. 4. The difference in (left) subgrid-scale, (center) grid-scale, and (right) total cloud liquid water path ( $\mathrm{g} \mathrm{m}^{-2}$ ) between the WACI and LAERO simulations over the SE region at (top) 36 , (middle) 12 , and (bottom) $4 \mathrm{~km}$.

compared to $36 \mathrm{~km}$ grid spacing clouds, which may lead to stronger moisture competition at $12 \mathrm{~km}$ grid spacing that reinforces the loss of grid-scale LWP from ACI.

Another important distinction that needs to be addressed between grid-scale and subgrid-scale ACI impacts is the relative strength of these simulated cloud types on the total change in cloud processes. As mentioned in Glotfelty et al. (2019), at $12 \mathrm{~km}$ grid spacing on average subgrid-scale clouds appear more sensitive to ACI than grid-scale clouds, due to nonlinear interactions of grid-scale microphysics with other processes. As a result of these differences, the subgrid-scale clouds experience a more uniform ACI impact compared to the gridscale clouds that experience much greater perturbations (Figs. 3 and 4). Due to the differences in uniformity between grid-scale and subgrid-scale ACI, comparing the mean LWP changes in the $\mathrm{SE}$ and FC regions provides the impression that subgrid-scale ACI processes are either dominant or comparable to grid-scale ACI process at each grid spacing. However, this is not the case if the maximum impact at each grid spacing is examined. For example, in the SE region the maximum LWP enhancement at $36 \mathrm{~km}$ grid spacing is $83.5 \mathrm{~g} \mathrm{~m}^{-2}$ for subgrid-scale clouds and $74.5 \mathrm{~g} \mathrm{~m}^{-2}$ for grid-scale clouds; at $12 \mathrm{~km}$ the maximum LWP enhancement is $55.7 \mathrm{~g} \mathrm{~m}^{-2}$ for subgrid-scale clouds and $107.9 \mathrm{~g} \mathrm{~m}^{-2}$ for grid-scale clouds; and at $4 \mathrm{~km}$ grid spacing the maximum LWP enhancement is $40.9 \mathrm{~g} \mathrm{~m}^{-2}$ for subgridscale clouds and $131.9 \mathrm{~g} \mathrm{~m}^{-2}$ for grid-scale clouds. Based on these values, it would appear that grid-scale-cloud processes dominate at 12 and $4 \mathrm{~km}$ grid spacing. However, this analysis may also be somewhat misleading, since the types of clouds simulated by the subgrid-scale and grid-scale parameterizations are different (e.g., cumulus versus cumulus and stratiform clouds). A visual inspection of both Figs. 3 and 4 shows that LWP-change patterns tend to show greater strength (i.e., absolute magnitude and spatial coverage) in subgrid-scale ACI impacts at $36 \mathrm{~km}$ grid spacing, greater strength in grid-scale ACI impacts at $4 \mathrm{~km}$ grid spacing, and comparable strength of ACI impacts in both the grid-scale and subgrid-scale clouds at $12 \mathrm{~km}$ grid spacing, based on magnitudes and spatial coverage. From this analysis, it can be learned that $12 \mathrm{~km}$ grid spacing represents a transition grid spacing where subgrid-scale and grid-scale ACI processes are the most comparable and thus the most in conflict.

\section{b. Scale dependency of cloud lifetime}

The decreasing trend in LWP enhancements with decreased grid spacing in the eastern United States may indicate that the cloud lifetime effect becomes less relevant as clouds within the model are better resolved; however, the decline in subgrid scale cloud processes at finer resolutions makes this difficult to discern. To determine if the cloud lifetime effect is indeed weakening at finer resolutions, we define a cloud time-scale parameter $(\tau)$, for grid-scale and subgrid-scale clouds, as the 
TABLE 3. Cloud time-scale values of the WACI and LAERO simulations.

\begin{tabular}{|c|c|c|c|c|c|c|c|}
\hline \multirow[b]{2}{*}{ Region } & \multirow[b]{2}{*}{ Resolution (km) } & \multicolumn{3}{|c|}{ Subgrid scale } & \multicolumn{3}{|c|}{ Grid scale } \\
\hline & & WACI & LAERO & $\Delta \tau$ & WACI & LAERO & $\Delta \tau$ \\
\hline \multirow[t]{3}{*}{ NE } & 36 & 2.08 & 1.25 & 0.83 & 26.51 & 24.56 & 1.95 \\
\hline & 12 & 2.87 & 2.20 & 0.67 & 23.37 & 22.17 & 1.20 \\
\hline & 4 & 3.55 & 2.58 & 0.97 & 22.13 & 21.64 & 0.49 \\
\hline \multirow[t]{3}{*}{ SE } & 36 & 1.35 & 1.07 & 0.28 & 33.71 & 22.66 & 11.05 \\
\hline & 12 & 2.01 & 1.43 & 0.58 & 29.38 & 24.90 & 4.48 \\
\hline & 4 & 2.21 & 1.49 & 0.72 & 21.60 & 20.86 & 0.74 \\
\hline \multirow[t]{4}{*}{ NMS } & 36 & 2.09 & 1.76 & 0.33 & 41.23 & 39.48 & 1.75 \\
\hline & 12 & 3.05 & 2.60 & 0.45 & 31.05 & 29.03 & 2.02 \\
\hline & 4 & 3.37 & 2.72 & 0.65 & 22.14 & 23.94 & -1.80 \\
\hline & 1 & 4.17 & 3.23 & 0.94 & 23.81 & 24.09 & -0.28 \\
\hline \multirow[t]{3}{*}{ FC } & 36 & 3.38 & 3.07 & 0.31 & 27.30 & 23.92 & 3.38 \\
\hline & 12 & 4.57 & 4.01 & 0.56 & 26.36 & 24.53 & 1.83 \\
\hline & 4 & 4.75 & 3.71 & 1.04 & 27.65 & 26.09 & 1.56 \\
\hline \multirow[t]{4}{*}{$\mathrm{NCO}$} & 36 & 3.22 & 4.52 & -1.30 & 21.08 & 17.51 & 3.57 \\
\hline & 12 & 3.50 & 3.66 & -0.16 & 19.03 & 18.45 & 0.58 \\
\hline & 4 & 3.72 & 2.95 & 0.77 & 21.18 & 19.18 & 2.00 \\
\hline & 1 & 5.28 & 3.98 & 1.30 & 27.02 & 25.10 & 1.92 \\
\hline
\end{tabular}

total grid-scale or subgrid-scale suspended liquid water and ice in the atmosphere (i.e., the sum of cloud water, cloud ice, rain, snow, and graupel suspended in the atmosphere) $\left(\mathrm{g} \mathrm{m}^{-2}\right) \mathrm{di}-$ vided by the hourly grid-scale or subgrid-scale precipitation rate $\left(\mathrm{g} \mathrm{m}^{-2} \mathrm{~h}^{-1}\right)$. This is similar to the cloud time-scale parameter defined in Ma et al. (2015), which defines $\tau$ as the LWP divided by the precipitation rate. We use total suspended liquid and ice in order to avoid missing the impacts of mixed phase clouds that dominate the western U.S. regions. The mean $\tau$ values of all five regions at each grid spacing for both grid-scale and subgrid-scale clouds, as well as the differences in $\tau$ values between the WACI and LAERO simulations $(\Delta \tau)$ are listed in Table 3. Boxplot distributions of the average $\tau$ values in each domain grid cell are also shown in Fig. 5. Note that grid cells experiencing less than $0.001 \mathrm{~g} \mathrm{~m}^{-2} \mathrm{~h}^{-1}$ of precipitation on average during the period are ignored to avoid numerically unrealistic $\tau$ values.

In general, the mean grid-scale $\Delta \tau$ declines consistently with decreasing grid spacing for the $\mathrm{NE}, \mathrm{SE}$, and $\mathrm{FC}$ regions. Both the NMS and NCO regions experience complex nonmonotonic changes in mean grid-scale $\Delta \tau$ values. The mean grid-scale $\Delta \tau$ values for the NMS area increase slightly from $1.75 \mathrm{~h}$ at $36 \mathrm{~km}$ to $2.02 \mathrm{~h}$ at $12 \mathrm{~km}$ and then become negative at 4 and $1 \mathrm{~km}$ grid spacing. A negative $\Delta \tau$ value indicates that ACI reduce the cloud lifetime rather than increasing it. In the NMS region, this nonmonotonic pattern could be the result of either model chaos (Ancell et al. 2018) or complex interactions of other ACI process, since this region covers a small spatial extent. For the NCO domain, the mean grid-scale $\Delta \tau$ value rapidly declines from $3.57 \mathrm{~h}$ at $36 \mathrm{~km}$ grid spacing to $0.58 \mathrm{~h}$ at $12 \mathrm{~km}$, before increasing to a relatively consistent $\sim 2.0-1.9 \mathrm{~h}$ at 4 and $1 \mathrm{~km}$ grid spacing. This trend could also be due to model chaos at this small scale, or may be due to changes in how clouds are resolved or differences in moisture competition at different grid spacings. The boxplot distributions in Fig. 5 show considerable overlap in the grid-scale cloud $\tau$ distributions between the WACI and LAERO simulations. However, nearly all regions show a shift to lower $\tau$ values at the higher end of the distributions in the LAERO simulations, indicating that the cloud-lifetime effect has the greatest impact on longer lived/weakly precipitating clouds. The overlap in the grid-scale cloud $\tau$ distributions increase with decreased grid spacing confirming the decreasing trend in the mean $\Delta \tau$ values seen for most regions in Table 3 .

The mean subgrid-scale cloud $\Delta \tau$ between the WACI and LAERO simulations show the opposite trend with a slight increase in $\Delta \tau$ values with deceased grid spacing. This slight increase in $\Delta \tau$ occurs because the subgrid-scale parameterization is simulating weaker convection at smaller grid spacings. The NCO region stands out as having the most unique pattern, with ACI resulting in reduced subgrid-scale cloud lifetimes at 36 and $12 \mathrm{~km}$ grid spacing. This strong reduction in subgrid-scale lifetime, with increased aerosol levels, likely indicates that the NCO region may potentially experience either convective invigoration from aerosols at 36 and $12 \mathrm{~km}$ grid spacing or enhanced snow riming from greater amounts of suspended liquid water (Igel et al. 2013; Thompson and Eidhammer 2014). The importance of the alluded convective invigoration or snow riming from the subgrid-scale clouds then begins to weaken as cumulus clouds become more resolved and less parameterized at 4 and $1 \mathrm{~km}$ grid spacing. One aspect of the thermodynamic invigoration effect is an extension of the cloud lifetime effect, wherein the increase in smaller cloud droplets from elevated aerosol levels allows for greater freezing within the storm that releases latent heat energy strengthening the convection (e.g., Rosenfeld et al. 2008). The subgrid-scale $\tau$ distributions in Fig. 5 show less overlap between the WACI and LAERO simulations than the grid-scale $\tau$ distributions, with the shift to smaller $\tau$ values in the LAERO simulations persisting into smaller grid spacings. These distributions also 


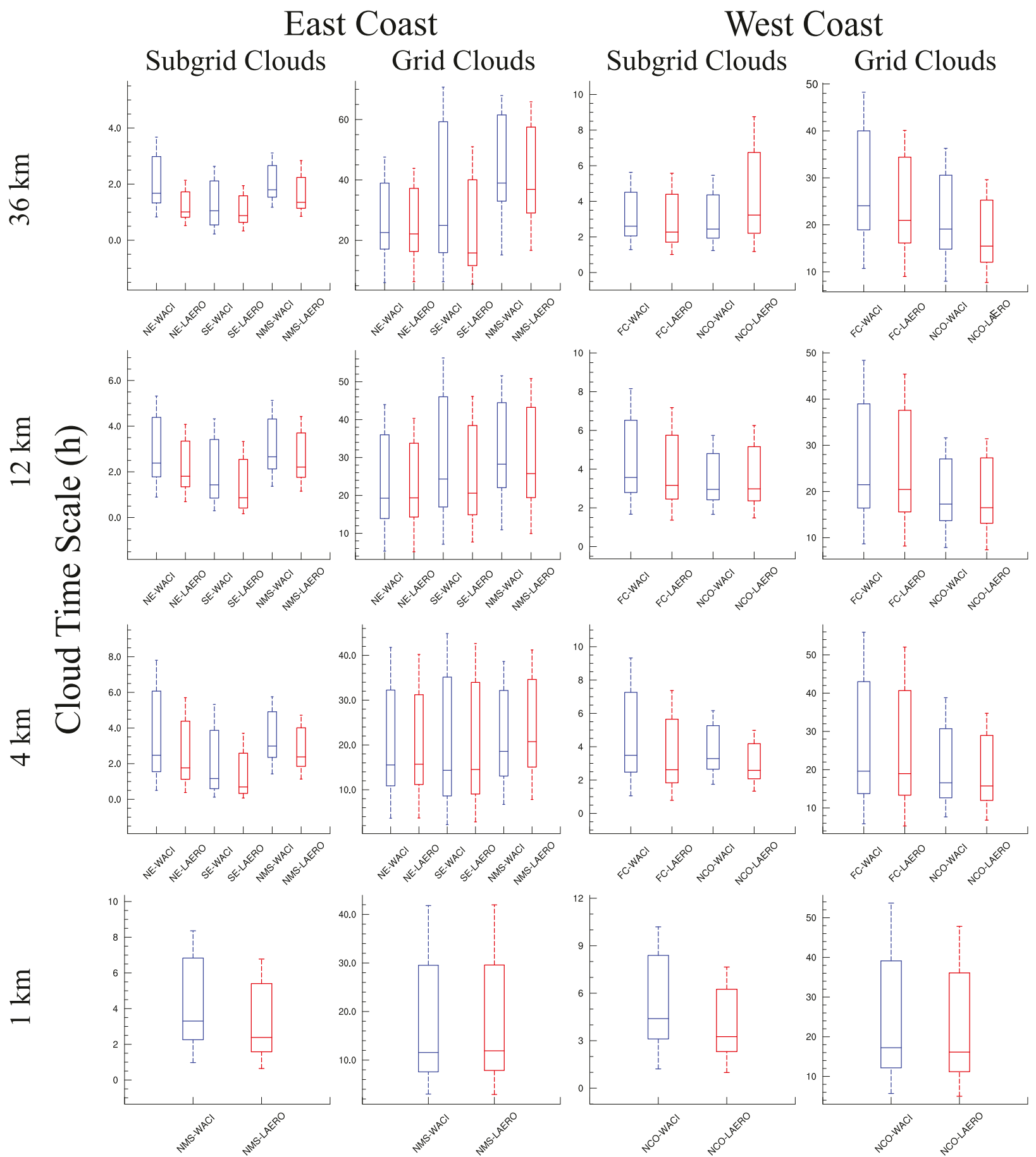

FIG. 5. Boxplot distributions of the average grid-scale and subgrid-scale cloud time-scale parameter (h) in each cell for the WACI and LAERO simulations at (top to bottom) 36,12, 4, and $1 \mathrm{~km}$ grid spacing. Maximum and minimum values in boxplots are upper and lower decile values.

confirm the unique behavior of subgrid scale ACI in the NCO region at 36 and $12 \mathrm{~km}$ grid spacing.

\section{c. Scale dependency of autoconversion versus accretion}

The main forcing behind the weakening cloud lifetime effect with decreased grid spacing, in most regions, is the relative importance of the cloud drop to raindrop autoconversion process (AUTO) to the cloud drop/raindrop accretion processes (ACCR) from the grid-scale and subgrid-scale microphysics schemes. This is because AUTO is more directly impacted by ACI (e.g., Ma et al. 2015). To illustrate this point, the domain mean ratio (in \%) of the AUTO tendency to the domain mean sum of the AUTO 
TABLE 4. Autoconversion ratio as a percentage.

\begin{tabular}{lcccccc}
\hline & & \multicolumn{2}{c}{ Subgrid scale } & & \multicolumn{2}{c}{ Grid scale } \\
\cline { 3 - 4 } \cline { 6 - 7 } Region & Resolution $(\mathrm{km})$ & WACI & LAERO & & WACI & LAERO \\
\hline NE & 36 & 9 & 17 & & 80 & 75 \\
& 12 & 11 & 14 & & 50 & 44 \\
& 4 & 19 & 17 & & 21 & 17 \\
SE & 36 & 8 & 15 & & 95 & 92 \\
& 12 & 12 & 13 & & 65 & 57 \\
& 4 & 22 & 18 & & 25 & 22 \\
NMS & 36 & 8 & 18 & & 100 & 97 \\
& 12 & 8 & 10 & & 81 & 78 \\
& 4 & 5 & 8 & & 30 & 27 \\
& 1 & 12 & 13 & & 20 & 23 \\
FC & 36 & 19 & 29 & & 91 & 73 \\
& 12 & 15 & 30 & & 78 & 58 \\
& 4 & 22 & 19 & & 25 & 39 \\
\multirow{2}{*}{ NCO } & 36 & 26 & 46 & & 82 & 57 \\
& 12 & 18 & 32 & & 73 & 40 \\
& 4 & 21 & 25 & & 26 & 22 \\
& 1 & 26 & 27 & 17 & 23 \\
\hline
\end{tabular}

and the ACCR tendencies for both grid-scale and subgrid-scale clouds from the WACI and LAERO simulations are listed in Table 4. Boxplot distributions of the AUTO ratio for each region and grid spacing are also show in Fig. 6. In the simulations conducted within this work, the impact of AUTO and ACCR are assumed to represent warm cloud processes; however, since the majority of clouds with the examined domains are mixed-phase the full cloud microphysical process at work may be more complex as illustrated in later sections.

The AUTO ratio values clearly indicate a difference in ACI behavior between the grid-scale and subgrid-scale clouds. Gridscale clouds see a decline in the relative importance of AUTO with decreasing grid spacing. Across all five regions, the relative importance of AUTO declines from mean values of $80 \%-100 \%$ at $36 \mathrm{~km}$ grid spacing to mean values of $17 \%-20 \%$ at $1 \mathrm{~km}$ grid spacing for the WACI simulations and for the LAERO simulations it declines from mean values of $57 \%-97 \%$ at $36 \mathrm{~km}$ grid spacing to mean values of $\sim 23 \%$ at $1 \mathrm{~km}$ grid spacing. In contrast, the subgrid-scale clouds have a variable fluctuation in the mean AUTO ratio of $5 \%-26 \%$ across differing grid spacing in the WACI simulation and a mean fluctuation of $8 \%-46 \%$ across differing grid spacing in the LAERO simulations. This behavior is mirrored in the distributions of Fig. 6. The shifts in the median AUTO ratio and the overall distributions show that generally autoconversion is less important in grid-scale clouds and more important in subgrid scale clouds in the LAERO simulations at 36 and $12 \mathrm{~km}$ grid spacing. At $4 \mathrm{~km}$ grid spacing, the shifts in the AUTO ratio distributions between the WACI and LAERO simulations are either reduced or change direction and at $1 \mathrm{~km}$ grid spacing the distributions show the strongest overlap.

The difference in behavior of the grid-scale and subgrid-scale clouds may result from either a physical process or may potentially be an artifact of the WRF-ACI modeling system. Both AUTO and ACCR are impacted by ACI. The AUTO formulations of Kogan (2013) in MSKF and Khairoutdinov and Kogan
(2000) from the MDM microphysics scheme both have an inverse proportionality of AUTO to cloud droplet number concentration. Therefore, when the cloud droplet number concentration (CDNC) level is reduced in the LAERO simulations the AUTO tendency should increase assuming all other parameters remain equal. The increased AUTO allows more cloud droplets to grow into raindrops and the simulated rainwater mass increases. The Khairoutdinov and Kogan (2000) ACCR formulation, used by both the MSKF and MDM parameterizations, represents ACCR as a direct function of cloud and rainwater mass. Thus, the increase in rainwater mass from AUTO triggers an indirect increase in ACCR from ACI, assuming all other parameters remain equivalent. However, the treatment of clouds in MSKF and MDM differ. MDM has advected hydrometeors that move throughout the simulated domain, while MSKF clouds are simulated in a manner where they exist only in one gridbox column and have no interactions with neighboring cells. As a result of this difference, the AUTO and ACCR processes in the subgrid-scale clouds are more tightly linked than in grid-scale clouds, where movement of hydrometeors between neighboring grid cells can begin to decouple the AUTO and ACCR processes.

To provide further insights into the factors impacting the changes in AUTO ratios, the domain mean column integrated grid-scale and subgrid-scale AUTO and ACCR tendencies from both the LAERO and WACI simulations are listed in Table S2. For the subgrid-scale clouds, the decrease in aerosol levels in the LAERO simulations increases both the AUTO and ACCR tendencies due to the tight linkage of these processes in the subgrid-scale microphysics parameterization. At coarser grid spacing, the increase in subgrid-scale AUTO is larger compared to the increase in subgrid-scale ACCR from reduced aerosol levels, leading to the higher subgrid-scale AUTO ratios in the LAERO simulation at coarser grid spacing. At coarser grid spacing, the grid-scale AUTO tendencies counterintuitively decrease in the LAERO simulation, while the grid-scale ACCR tendencies increase. This results in the decrease of grid-scale AUTO ratios in the LAERO simulation. Since CDNC is nearly always reduced in the LAERO simulations because aerosol levels are prescribed (See Figs. S7 and S8), the decrease in grid scale AUTO tendencies can only occur in response to reductions in cloud water mass. Therefore, the decreased LWP in the LAERO simulations could occur in response to either losses of moisture from competition with the subgrid scale microphysics or from a feedback cycle of increased ACCR levels leading to reduced cloud water that in turn reduces AUTO. In either case, this finding provides further evidence that the grid-scale AUTO and ACCR process are less tightly linked than their subgrid scale counterparts. These findings also potentially indicate some regime dependence of ACI on the AUTO and ACCR processes, since reduced aerosol levels in the LAERO simulations at finer grid spacing (i.e., 1 and $4 \mathrm{~km}$ ) lead to dual increases in grid scale AUTO and ACCR that mirror the changes in the subgrid-scale microphysics.

\section{d. Scale dependency of aerosol-cloud interaction impacts on cloud ice}

The domain-wide mean changes in cloud ice water path (IWP) between the WACI and LAERO simulations for the 


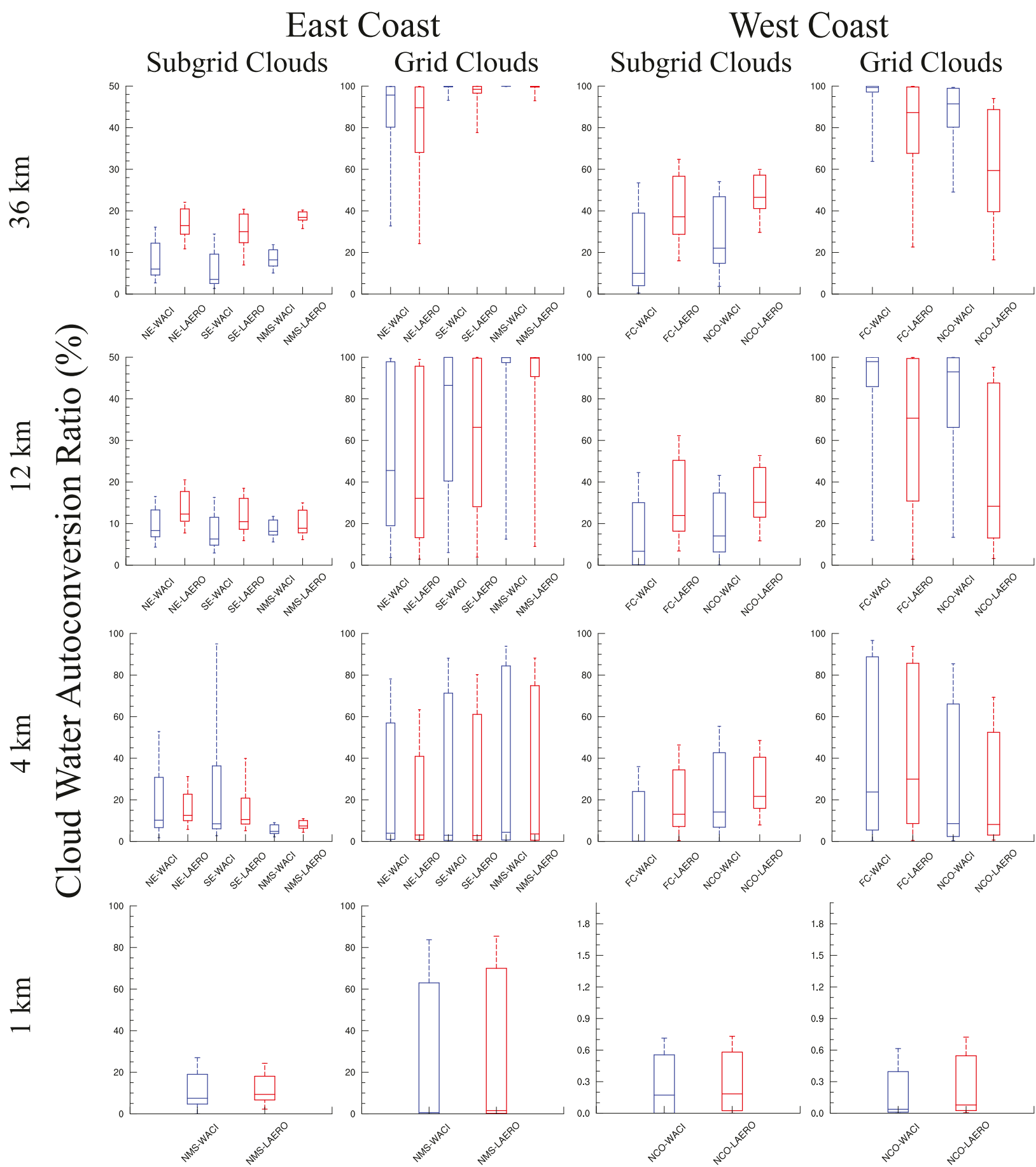

FIG. 6. Boxplot distributions of the average grid scale and subgrid scale cloud water autoconversion ratio (\%) in each cell for the WACI and LAERO simulations at (top to bottom) $36,12,4$, and $1 \mathrm{~km}$ grid spacing. Maximum and minimum values in boxplots are upper and lower decile values.

NE, SE, NMS, FC, and NCO regions at 36, 12, 4, and $1 \mathrm{~km}$ grid spacing are shown in Fig. 7. For a more detailed analysis of IWP-impacts from ACI in different regimes, the difference in subgrid-scale, grid-scale, and total IWP between the WACI and LAERO simulations over the FC and SE regions are shown in Figs. 8 and 9, respectively. Unlike the LWP difference, the mean ACI impacts on IWP are variable between regions and grid spacing. Generally, the $\mathrm{NE}$ and $\mathrm{SE}$ regions have negligible mean IWP impacts from ACI, which result from cancellation between regions of increases and decreases 


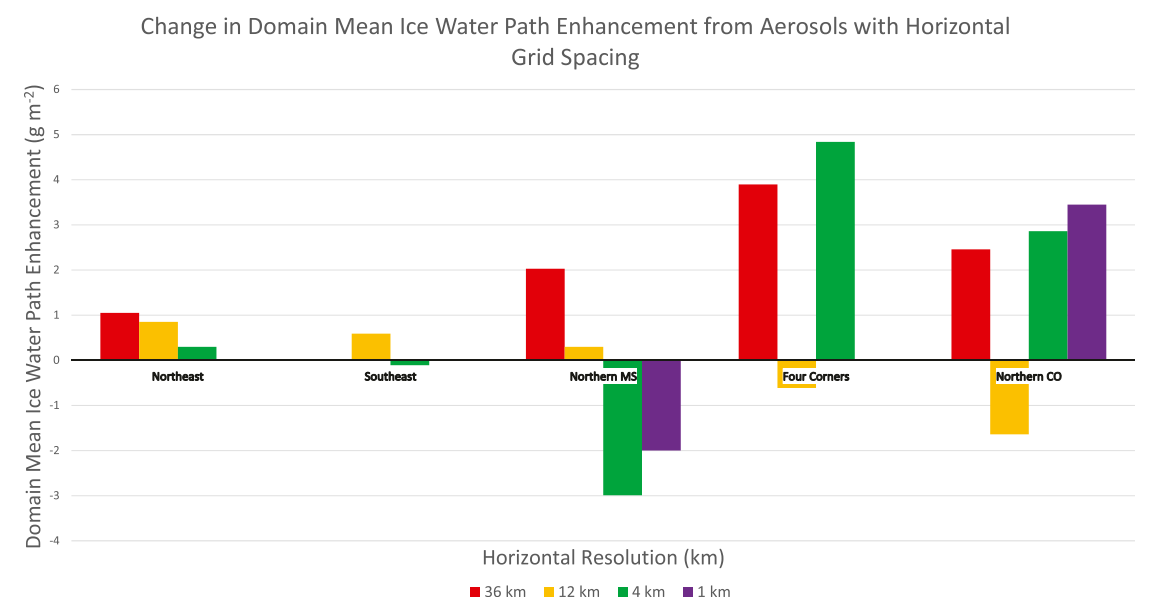

FIG. 7. The domain-wide mean change in cloud ice water path $\left(\mathrm{g} \mathrm{m}^{-2}\right)$ between the WACI and LAERO simulations for the NE, SE, NMS, FC, and NCO domains at 36 (red), 12 (gold), 4 (green), and $1 \mathrm{~km}$ (purple) grid spacing.

of IWP, as shown for the SE in Fig. 9. The "noisy" behavior of IWP from ACI in the eastern United States either indicates that most IWP changes induced by ACI are indirect or that IWP perturbations are caused by model chaos (Ancell et al. 2018). Since the impacts of ACI on IWP are localized, the smaller NMS domain experiences what appears to be strong shifts between IWP enhancements from coarse to fine grid spacing. In the FC and NCO domains, there are enhancements in IWP from ACI at every grid spacing, except $12 \mathrm{~km}$. These enhancements in IWP provide further evidence that the western U.S. regions may experience a thermodynamic invigoration effect from aerosols. This potential invigoration effect is clearest in Fig. 8 from the nearly uniform enhancement in grid-scale IWP at both 36 and $4 \mathrm{~km}$ grid spacing. In Fig. 7, the domain average change in IWP at $12 \mathrm{~km}$ stands out as having a very unique pattern compared to the other grid spacing values. This likely results from the strong competition between grid-scale and subgrid-scale processes at $12 \mathrm{~km}$ grid spacing. Figures 6 and 7 also show that the grid-scale changes in IWP dominate the total change in IWP. As in Glotfelty et al. (2019), the subgrid-scale IWP is enhanced at the coarser resolutions (top panels in column 1 of Figs. 8 and 9) because IWP enhancements are directly tied to LWP enhancements in the subgrid-scale microphysics.

\section{e. Scale dependency of aerosol-cloud interaction impacts on precipitation}

The domain-wide mean changes in precipitation between the WACI and LAERO simulations for the NE, SE, NMS, FC, and NCO regions at $36,12,4$, and $1 \mathrm{~km}$ grid spacing are shown in Fig. 10. The eastern U.S. regions show significant suppression of precipitation from ACI, with the most significant impacts at $36 \mathrm{~km}$ grid spacing due to the dominance of subgrid-scale precipitation at this resolution. If $12 \mathrm{~km}$ grid spacing is ignored due to its unique behavior, in the eastern U.S. regions there is a general decline in the suppression of precipitation with decreased grid spacing, both due to the transition from a grid spacing where subgrid-scale clouds are dominant to a grid spacing where grid-scale clouds are dominant and due to the weakening of the cloud-lifetime effect with decreased grid spacing. The western U.S. regions experience relatively insignificant domain mean net precipitation impacts from ACI due to complex patterns of increases and decreases in precipitation that offset. This likely arises because of significant competition for limited moisture between the grid-scale and subgrid-scale clouds, and because the clouds over these regions are generally mixed phase. As a result, the cloud lifetime, snow riming by excess cloud water, and potentially the thermodynamic invigoration effects are occurring simultaneously. Differences in aerosol speciation and aerosol loadings between the eastern and western United States may also play a limited role in the differences in ACI impacts between both regions. As with the comparison in Fig. 7, the impacts of ACI on precipitation at $12 \mathrm{~km}$ grid spacing stand out compared to all other grid spacings due to the effect of enhanced competition for moisture, with opposite behavior in the eastern and western United States. Also, it is important to note that the western U.S. domain contains fewer grid cells that experience precipitation and thus the domain average impact may be somewhat diluted by averaging excess grid cells with minimal values.

For a more detailed analysis of precipitation impacts in the western United States, the change in accumulated subgridscale, grid-scale, and total precipitation between the WACI and LAERO simulations at 36, 12, and $4 \mathrm{~km}$ grid spacing over the FC region is shown in Fig. 11. There is a clear enhancement of subgrid-scale precipitation at $36 \mathrm{~km}(0.49 \mathrm{~mm})$ and $12 \mathrm{~km}$ $(0.73 \mathrm{~mm})$ grid spacing. However, the increases in subgridscale precipitation are compensated by decreases in grid-scale precipitation $(0.46 \mathrm{~mm}$ at $36 \mathrm{~km}$ and $1.51 \mathrm{~mm}$ at $12 \mathrm{~km})$. The loss of grid-scale precipitation appears to be the result of losses in moisture to the subgrid-scale clouds rather than the cloudlifetime effect, since the grid-scale LWP decreases rather than increases (Fig. 3). At $4 \mathrm{~km}$ grid spacing, the pattern switches to a domain mean reduction $(0.50 \mathrm{~mm})$ in subgrid-scale precipitation, while grid-scale precipitation is enhanced on domain average $(0.45 \mathrm{~mm})$. The decrease in subgrid-scale precipitation is clearly due to the cloud-lifetime effect, as evidenced by 


\section{Subgrid Scale}
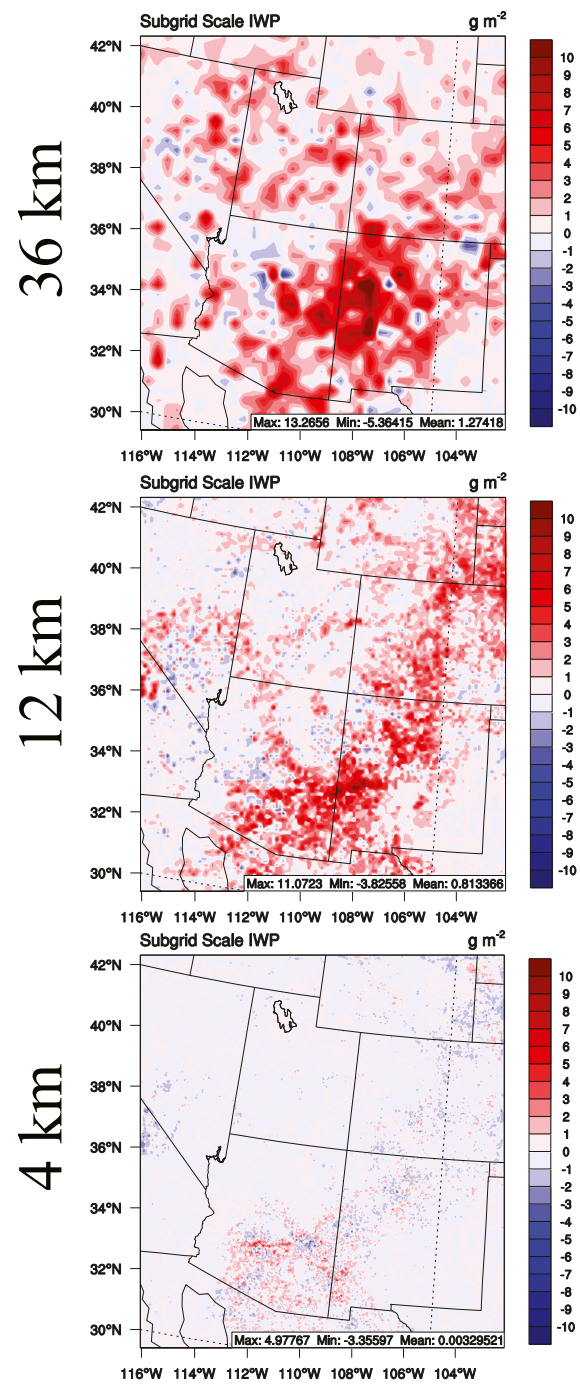

Grid Scale
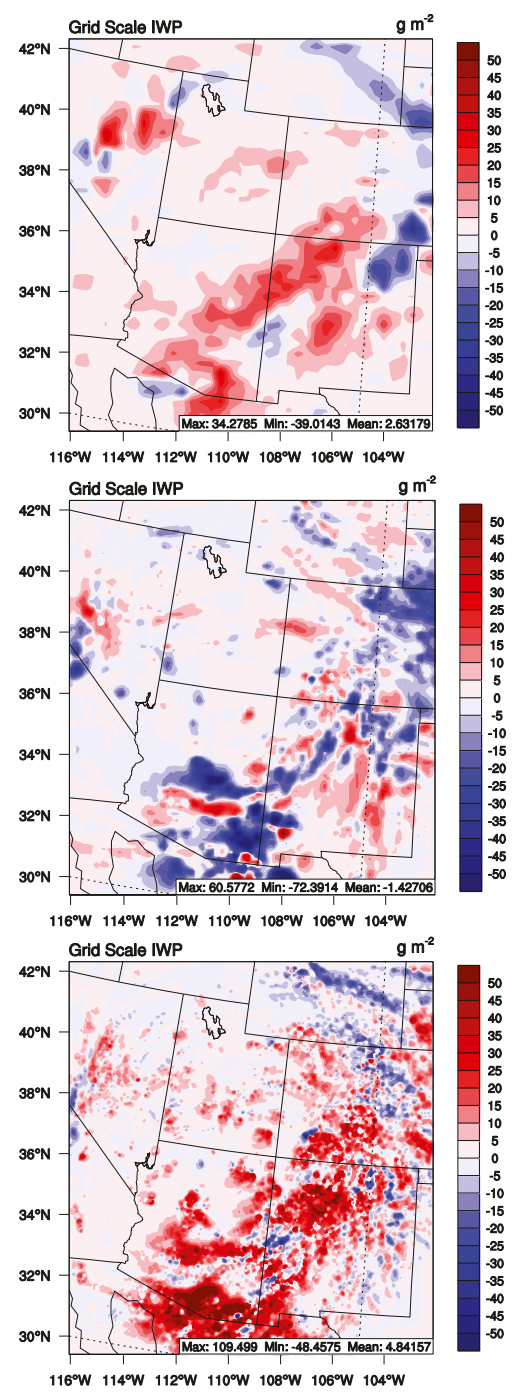

\section{Total}
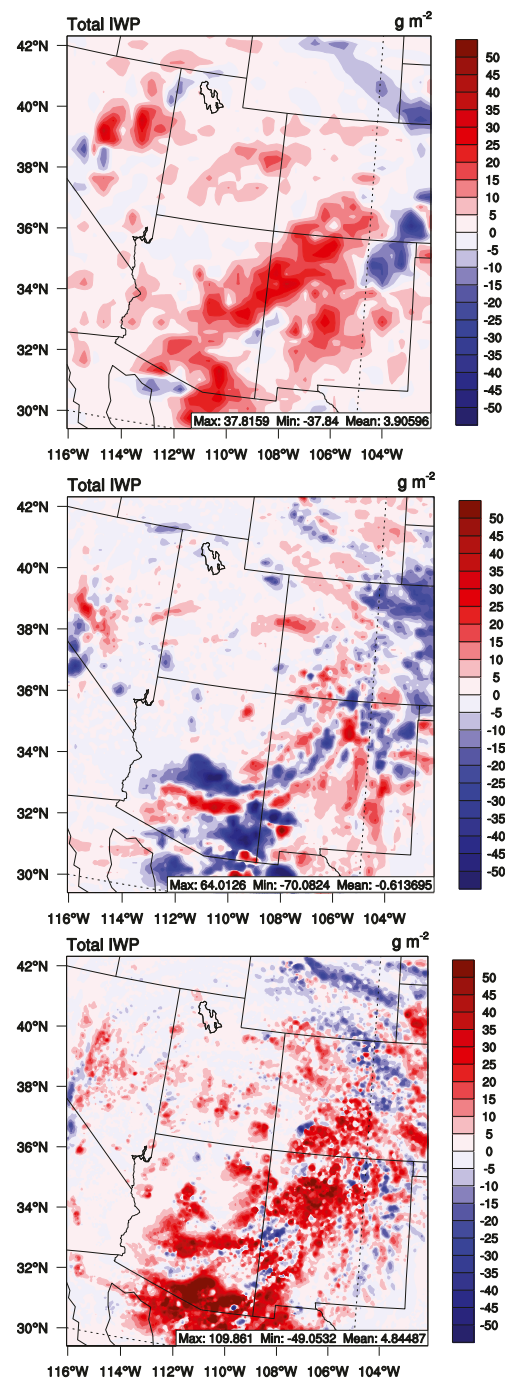

FIG. 8. The difference in (left) subgrid-scale, (center) grid-scale, and (right) total cloud ice water path $\left(\mathrm{g} \mathrm{m}^{-2}\right.$ ) between the WACI and LAERO simulations over the FC region at (top) 36 , (middle) 12, and (bottom) $4 \mathrm{~km}$.

the increase in subgrid-scale LWP (Fig. 3). The domainmean change in precipitation at $4 \mathrm{~km}$ grid spacing clearly shows that the combination of the cloud-lifetime effect in subgrid-scale clouds and either thermodynamic invigoration effects or snow riming effects in the grid-scale clouds compensate one another, leading to a negligible mean impact $(-0.08 \mathrm{~mm})$.

The change in accumulated subgrid-scale, grid-scale, and total precipitation between the WACI and LAERO simulations at 36,12 , and $4 \mathrm{~km}$ grid spacing over the $\mathrm{SE}$ region is shown in Fig. 12. At every grid spacing, subgrid-scale precipitation is suppressed due to the cloud-lifetime effect. The dominance of the cloud-lifetime effect in this region likely occurs because warm cloud processes dominate in this region, especially for subgrid-scale clouds. The change in grid-scale precipitation is variable at each grid spacing; however, one common theme is significant perturbations in the precipitation response to ACI. Over the SE region, it is difficult to diagnose whether or not the enhancements in grid-scale precipitation are the result of potential thermodynamic invigoration effects, perturbations due to moisture competition between grid-scale and subgrid-scale clouds, or whether these enhancements are simply numerical artifacts caused by differences in atmospheric state between the WACI and LAERO simulations. At both 36 and $4 \mathrm{~km}$ grid spacing, the domain mean change in grid-scale precipitation is negative indicating that the cloud-lifetime effect is relevant in grid-scale clouds. In contrast, the increase in domain average grid-scale precipitation at $12 \mathrm{~km}$ grid spacing is likely a consequence of model perturbations from strong moisture competition effects or numerical noise at this grid spacing. 

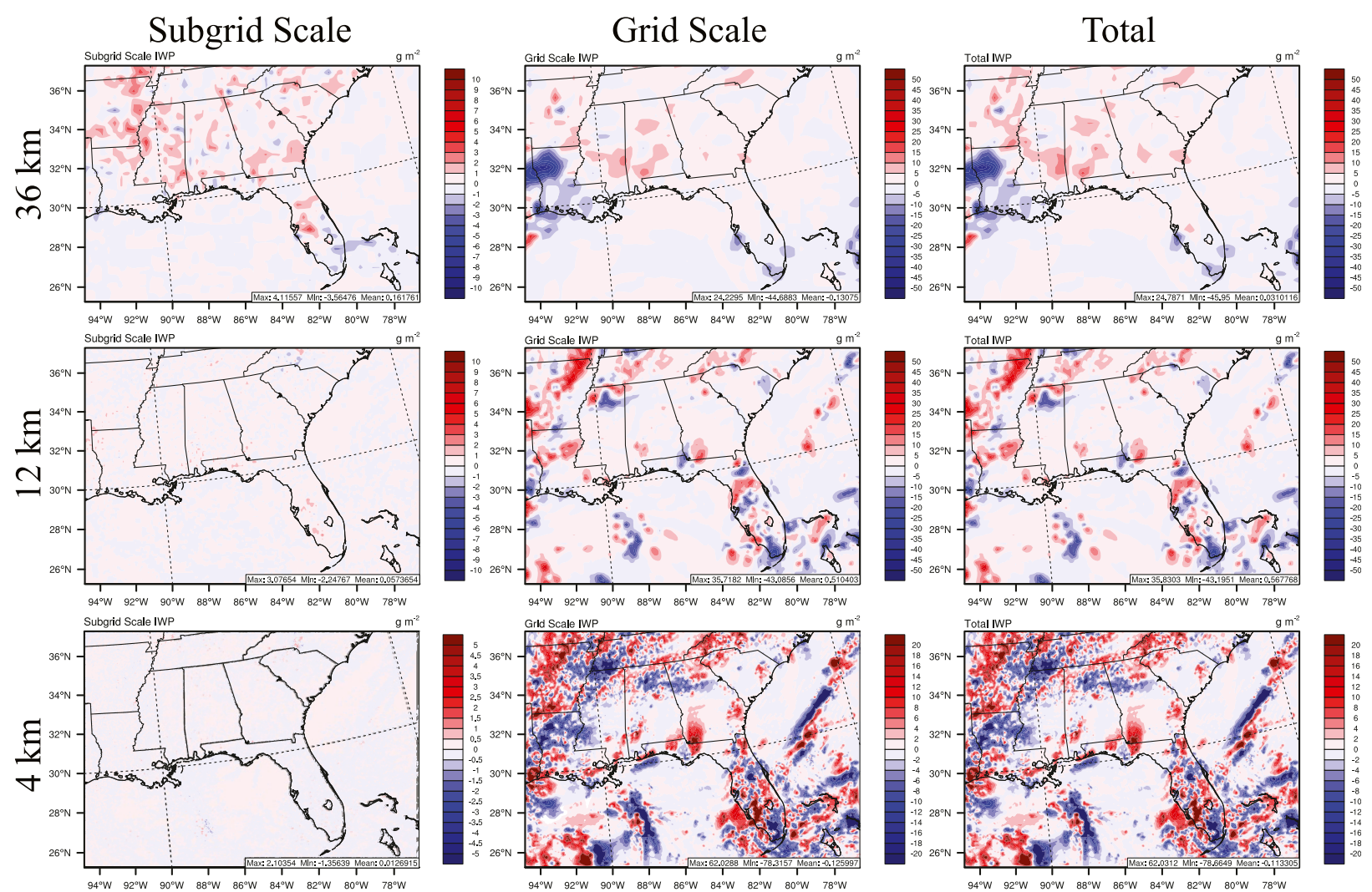

FIG. 9. The difference in (left) subgrid-scale, (center) grid-scale, and (right) total cloud ice water path $\left(\mathrm{g} \mathrm{m}^{-2}\right)$ between the WACI and LAERO simulations over the SE region at (top) 36 , (middle) 12 , and (bottom) $4 \mathrm{~km}$.

\section{f. Scale dependency of aerosol-cloud interaction impacts on radiation}

The domain-wide mean changes in longwave cloud forcing (LWCF) and shortwave cloud forcing (SWCF) between the WACI and LAERO simulations for the NE, SE, NMS, FC, and $\mathrm{NCO}$ regions at $36,12,4$, and $1 \mathrm{~km}$ grid spacing are shown in
Fig. 13. ACI-induced changes in SWCF are often larger than changes in LWCF, with a few grid spacings experiencing comparable changes. In the NE, NMS, and FC regions the LWCF impact from ACI declines with decreasing grid spacing. The SE and NCO regions have LWCF impacts that maximize at $12 \mathrm{~km}$ grid spacing, but subsequently decline to negligible

Domain Mean Change in Precipitation Due to Aerosol Indirect Effects

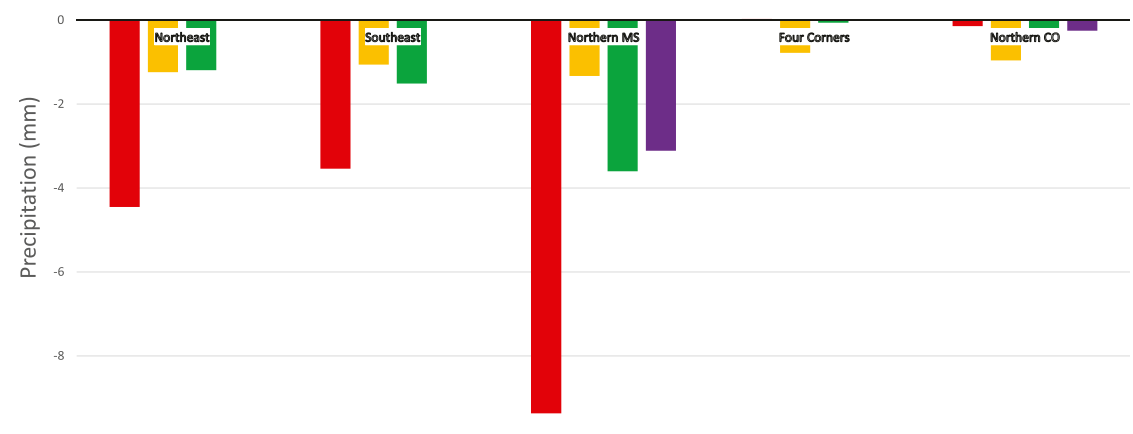

Horizontal Resolution ( $\mathrm{km}$ )

- $36 \mathrm{~km} \quad \square 12 \mathrm{~km} \quad \square \mathrm{km} \quad \because 1 \mathrm{~km}$

FIG. 10. The domain-wide mean change in precipitation $(\mathrm{mm})$ between the WACI and LAERO simulations for the NE, SE, NMS, FC, and NCO domains at 36 (red), 12 (gold), 4 (green), and $1 \mathrm{~km}$ (purple) grid spacing. 


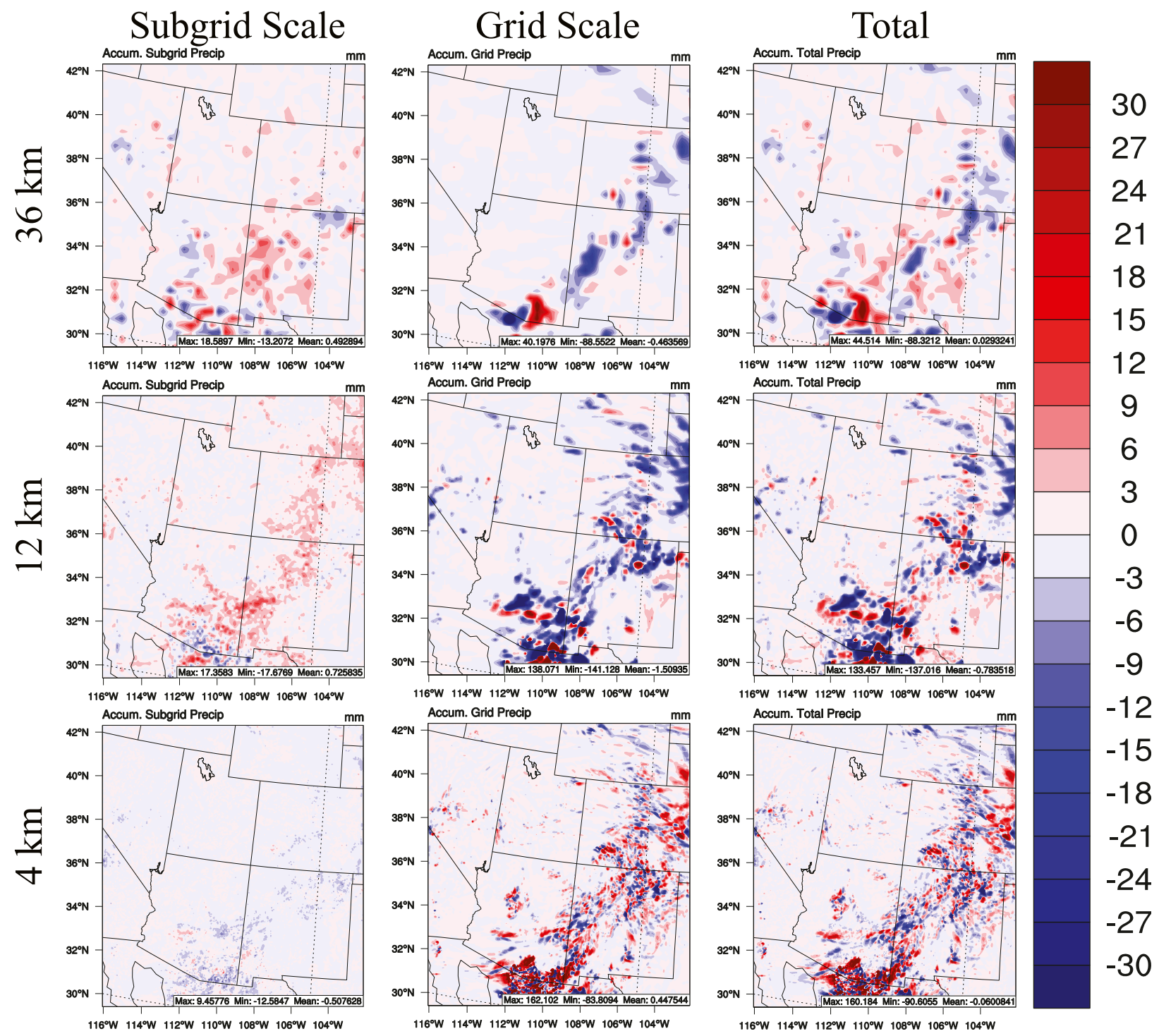

FIG. 11. The difference in (left) subgrid-scale, (center) grid-scale, and (right) total precipitation (mm) between the WACI and LAERO simulations over the FC region at (top) 36 , (middle) 12 , and (bottom) $4 \mathrm{~km}$.

values at 4 and $1 \mathrm{~km}$ grid spacing. The minimal mean signal in LWCF from ACI across the different regions when grid spacing is reduced does not occur as a result of minimal impacts, but rather the compensation of many perturbations in LWCF. These perturbations typically correspond to perturbations in IWP from ACI, but other factors likely play a role in these changes. In contrast, SWCF has a slightly decreasing trend with decreased grid spacing in all five simulated regions. As discussed in Glotfelty et al. (2019), the impact of ACI on SWCF is the result of a combination of the aerosol-cloud-lifetime effect and also the cloud-albedo effect. The cloud-albedo effect describes the increase in scattering that results from reducing the average size of cloud droplets when aerosol levels are elevated. Since the aerosol concentrations in WRF-ACI do not change with model grid spacing, the general impact of the cloudalbedo effect is fairly consistent at each grid spacing. However, as discussed in section $4 \mathrm{~b}$, the cloud lifetime effect reduces with decreased grid spacing accounting for the slight decreasing trend in SWCF.

To further analyze the impacts of ACI on radiation, the differences in LWCF and SWCF between the WACI and LAERO simulations over the FC and SE regions are shown in Figs. 14 and 15, respectively. Changes in LWCF can occur in response to many factors including but not limited to changes in cloud water and ice distributions, cloud thickness, and changes in cloud optical properties. However, areas that show strong consistent increases in IWP at each grid spacing from either thermodynamic invigoration effects, snow riming from ACI, or numerical noise over the FC region (Fig. 8) typically result in the strongest increases in LWCF. SWCF consistently increases over the FC region at each grid spacing due to the cloud albedo and cloud lifetime effects. The LWCF impacts 

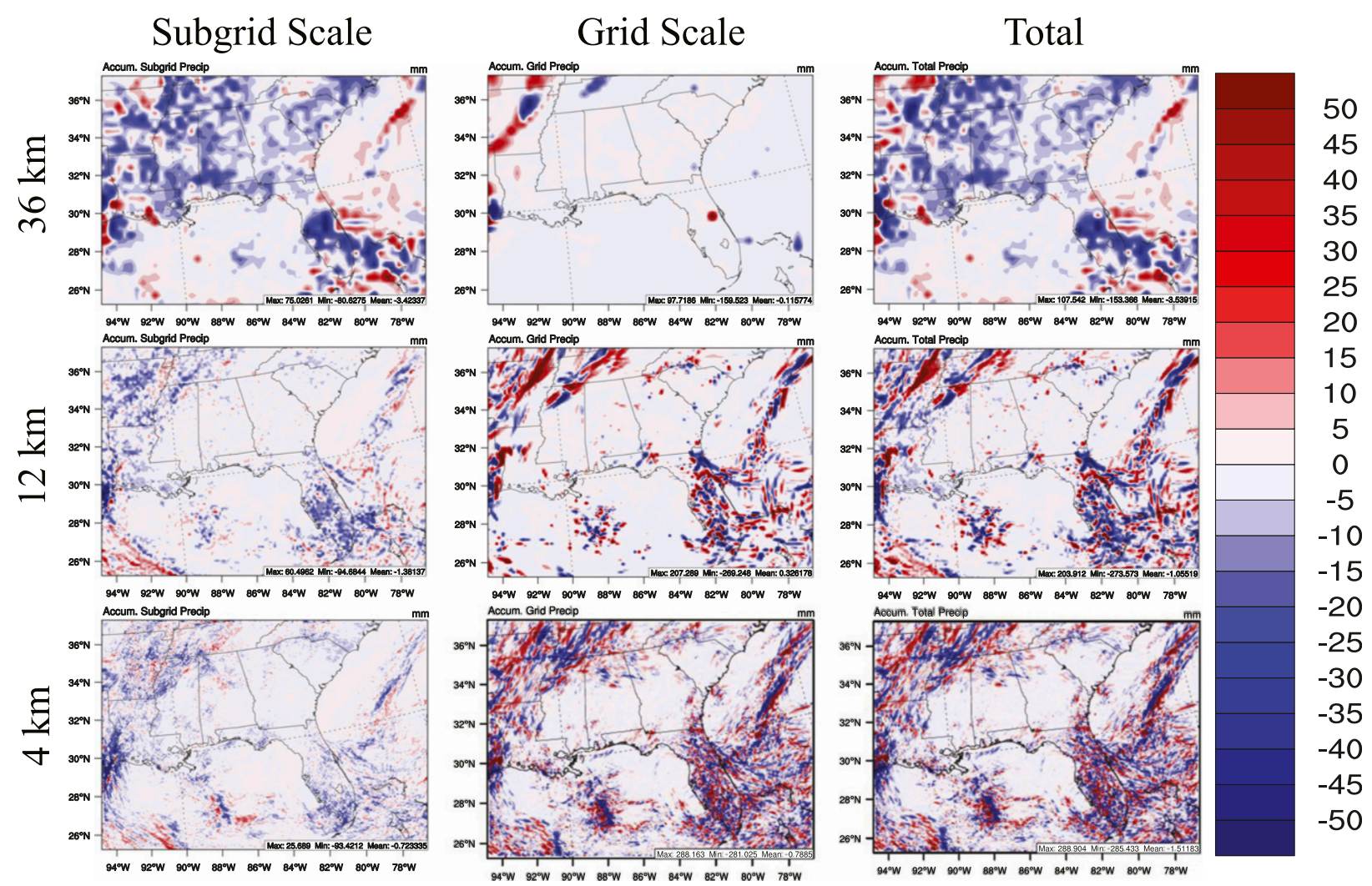

FIG. 12. The difference in (left) subgrid-scale, (center) grid-scale, and (right) total precipitation (mm) between the WACI and LAERO simulations over the SE region at (top) 36, (middle) 12, and (bottom) $4 \mathrm{~km}$.

from ACI over the SE show significant variation at differing grid spacing. These variations in LWCF patterns lead to the generally negligible domain-mean differences shown in Fig. 13. SWCF decreases on average in the SE at $36 \mathrm{~km}$ grid spacing due to reduced grid-scale cloud formation over the oceans from moisture competition (Fig. 4). This pattern does not exist at either 12 or $4 \mathrm{~km}$ grid spacing, which show an increase SWCF in response to ACI. Interestingly, at $12 \mathrm{~km}$ SWCF enhancements from ACI are maximized over both the FC and SE regions. This pattern is also present in the mean values of the NE and NCO regions from Fig. 13. Given that subgrid-scale and grid-scale cloud ACI processes are roughly equivalent at $12 \mathrm{~km}$ grid spacing, it is likely that the combined impact of both gridscale and subgrid-scale clouds maximize at $12 \mathrm{~km}$ grid spacing.

However, the maximization of SWCF impacts at $12 \mathrm{~km}$ grid spacing may not necessarily be a physical result. In the WRFACI system, aerosol levels are prescribed and thus aerosol levels are never depleted in response to uptake by clouds. As a result of this simplification, both grid-scale and subgrid-scale clouds have the same constant aerosol supply for aerosol activation/ice nucleation. In reality all clouds would compete for available aerosols that may be removed during precipitation events, indicating the SWCF maximum impact may be overstated. Additionally, this result may not necessarily occur when using a coupled meteorology-chemistry model because gradients in pollutant emissions and thus aerosol concentrations/ACI should intensify with decreasing grid spacing (Ma et al. 2015). This effect is not currently part of the WRF-ACI framework.

\section{Summary and conclusions}

In this work, the Weather Research and Forecasting Model with Aerosol-Climate Interactions (WRF-ACI) is used to investigate the scale dependency of ACI. This is accomplished by simulating two short-term periods, 17-24 June 2006 in the eastern United States to represent moisture rich regimes and 23-28 July 2006 in the western United States to represent moisture deficient regimes. To calculate the impacts of ACI, the WACI simulations that contain current climatological aerosol levels are compared against the LAERO simulations in which aerosol levels are reduced by $90 \%$ to represent clean conditions. The differences in LWP, IWP, precipitation, LWCF, and SWCF over the NE, SE, NMS, FC, and NCO domains between the WACI and LAERO simulations at 36, 12,4 , and $1 \mathrm{~km}$ (NMS and NCO only) grid spacing are compared to determine if ACI impacts vary with horizontal model grid spacing.

Domain-wide LWP is enhanced in WACI compared to LAERO for all regions at every grid spacing, indicating the dominance of the cloud-lifetime effect at all horizontal resolutions. However, the cloud-lifetime effect declines with increasing resolution due to an increase in the importance of the cloud drop/raindrop accretion process compared to the cloud drop to raindrop autoconversion process with decreased grid 

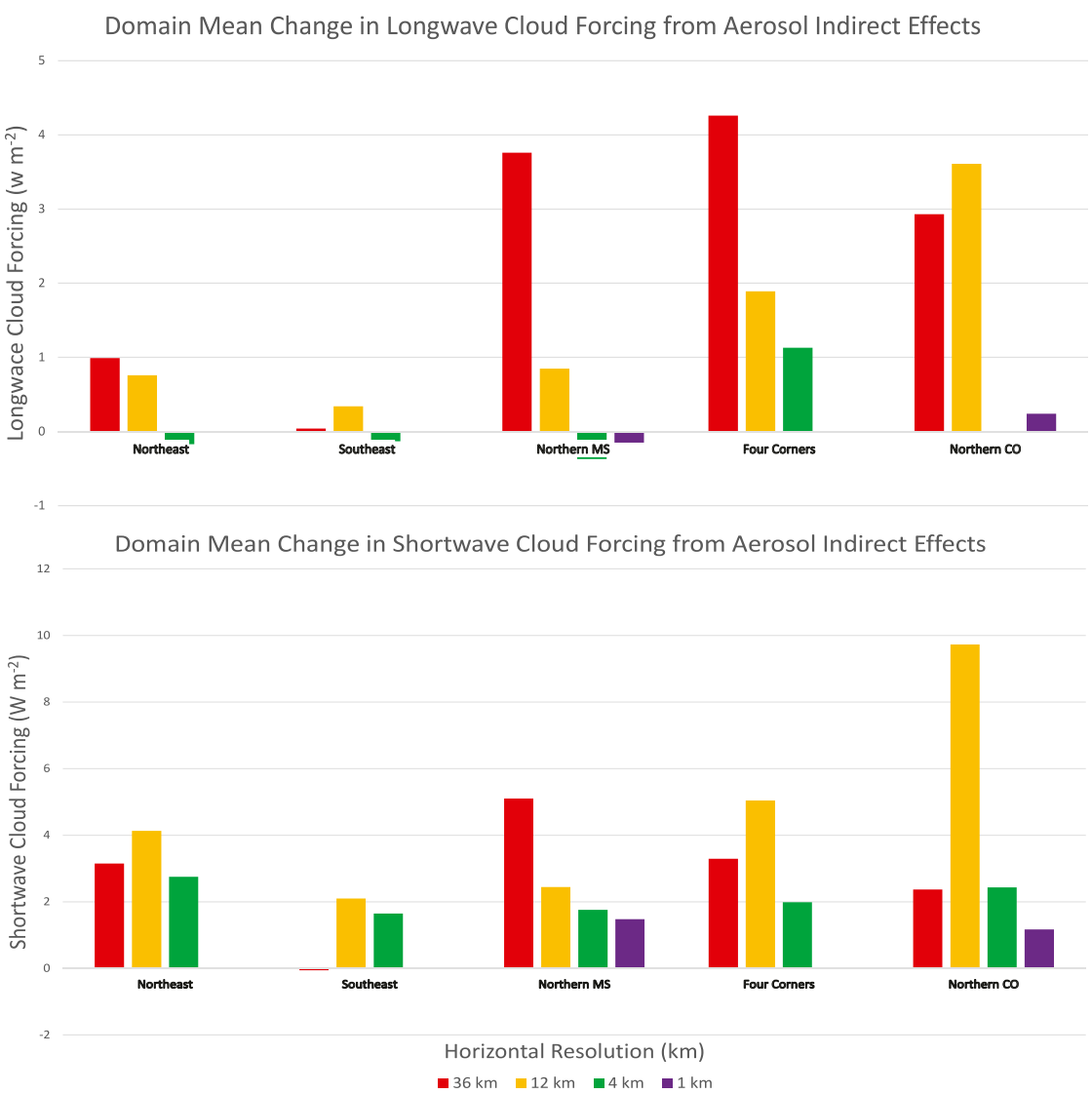

FIG. 13. The domain-wide mean change in (top) longwave cloud forcing and (bottom) shortwave cloud forcing $\left(\mathrm{W} \mathrm{m}^{-2}\right)$ between the WACI and LAERO simulations for the NE, SE, NMS, FC, and NCO domains at 36 (red), 12 (gold), 4 (green), and $1 \mathrm{~km}$ (purple) grid spacing.

spacing in grid-scale clouds. The cloud-lifetime effect is the dominant process controlling precipitation suppression by aerosols in the eastern United States. In the western United States, significant increases in LWP, IWP, and precipitation that potentially occur in response thermodynamic invigoration from aerosols or snow riming offset the impacts of the cloudlifetime effect, leading to a negligible total impact on precipitation from ACI. ACI impacts on LWCF are minor and become less relevant with decreased grid spacing due to localized offsetting perturbations. The impacts of ACI on SWCF are larger than those on LWCF due to a combination of enhancements from the cloud-albedo and cloud-lifetime effects. The cloudalbedo effect does not change considerably with grid spacing; however, the reduction in the cloud-lifetime effect with decreased grid spacing results in a slight decreasing trend in SWCF impacts from ACI with decreasing grid spacing.

At coarser grid spacing (i.e., $36 \mathrm{~km}$ grid spacing), ACI effects are impacted by competition for available moisture between both the grid-scale and subgrid-scale cloud parameterizations. This competition effect is stronger in the western United States compared to the eastern United States, and only diminishes when subgrid-scale clouds become less relevant at $4 \mathrm{~km}$. In this work, we found 1) subgrid-scale ACI processes to be dominant at $36 \mathrm{~km}$ grid spacing, 2) grid-scale ACI processes to be dominant at 4 and $1 \mathrm{~km}$ grid spacing, and 3) grid-scale and subgridscale ACI processes to be comparable at $12 \mathrm{~km}$ grid spacing. The strong competition between grid-scale and subgrid-scale ACI processes at $12 \mathrm{~km}$ result in unique ACI impacts. This type of result mirrors the seasonal simulation at $12 \mathrm{~km}$ grid spacing in Glotfelty et al. (2019). This strong competition between grid-scale and subgrid-scale processes at $12 \mathrm{~km}$ grid spacing complicate the understanding of ACI. Thus, these short-term results [and long-term results in Glotfelty et al. (2019)] suggest $12 \mathrm{~km}$ ACI results be treated with caution in the current WRF modeling system.

The WRF-ACI model system has some limitations, documented in Glotfelty et al. (2019), which may have an impact on the results. The most relevant of these limitations is the lack of communication between neighboring grid cells and retention of hydrometeors between time steps in the subgrid-scale microphysics scheme, which leads to generally uniform impacts of ACI from subgrid-scale processes compared to large perturbations in grid-scale processes. The use of prescribed aerosols in lieu of a full aerosol budget is also a limitation of the WRFACI system as the aerosol concentrations are not completely reflective of the atmospheric state and thus may overrepresent 


\section{LWCF}

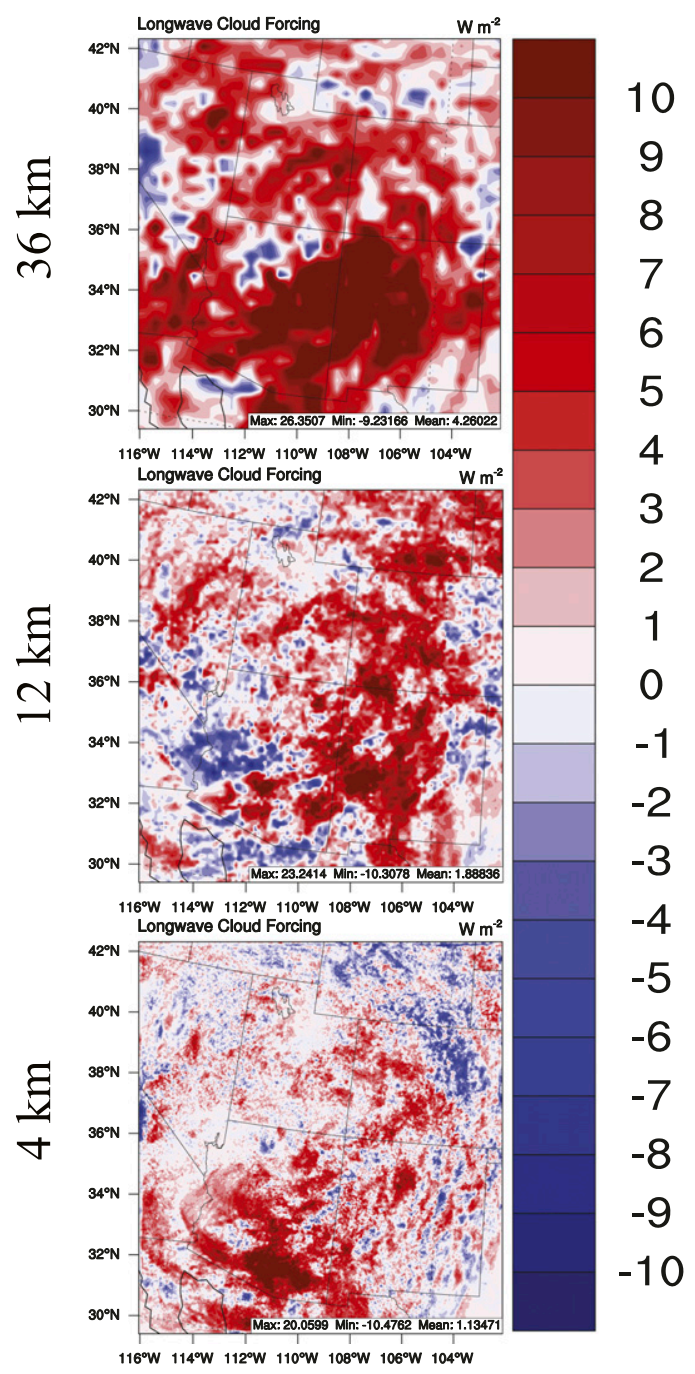

SWCF

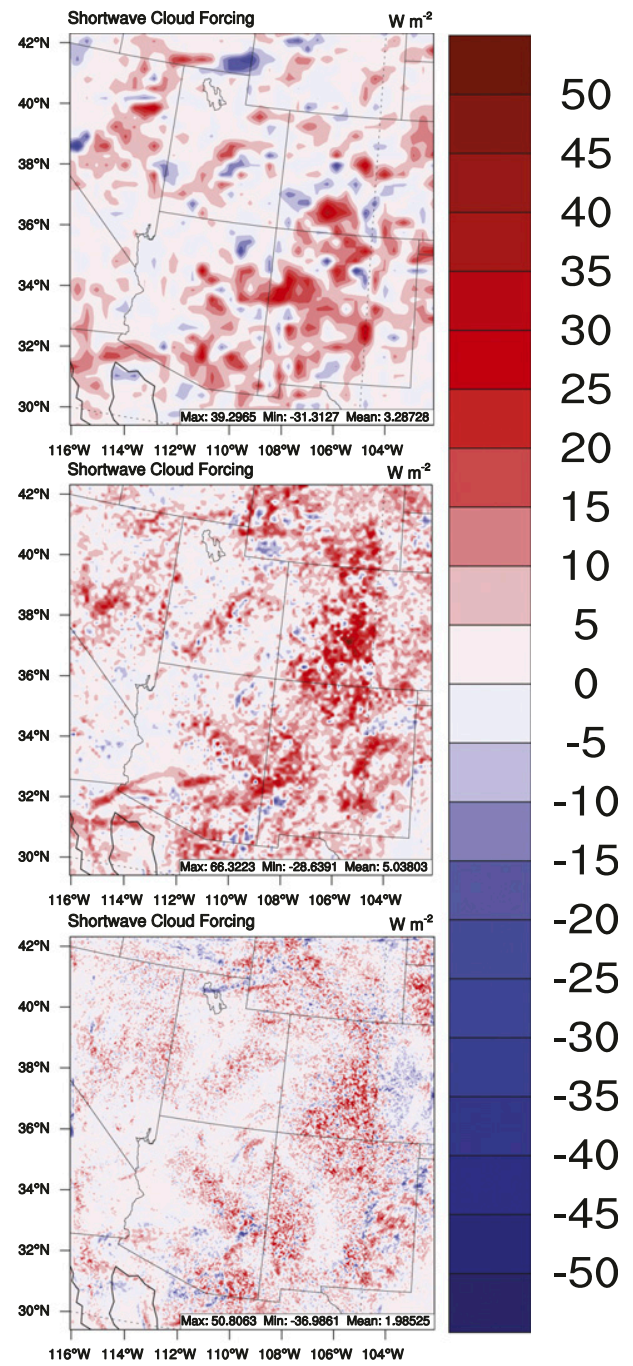

FIG. 14. The difference in (left) longwave cloud forcing and (right) shortwave cloud forcing ( $\left.\mathrm{W} \mathrm{m}^{-2}\right)$ between the WACI and LAERO simulations over the FC region at (top) 36, (middle) 12, and (bottom) $4 \mathrm{~km}$.

or underrepresent the aerosol levels of any grid cell at any given time. The use of prescribed aerosols may also partly contribute to the unique behavior of ACI-impacts at $12 \mathrm{~km}$ grid spacing, since grid-scale and subgrid-scale cloud processes are comparable and both microphysics schemes can draw from the same never-depleting aerosol concentrations for cloud processes. As discussed in Glotfelty et al. (2019), the magnitude of ACI impacts can also largely vary depending on the choice of autoconversion scheme in the cloud microphysics parameterizations, although this choice in autoconversion does not appear to impact the strength of grid-scale clouds relative to subgrid-scale clouds and thus would not likely impact the conclusions here. Additionally, the time periods simulated in this work were short term and only conducted during the Northern Hemisphere summer. Therefore, they may not necessarily reflect the climatological impacts of ACI on the full range of weather systems in the examined regions, other seasonal patterns in these regions, or be consistent with ACI impacts in other simulated regions. However, the results presented in this work are generally consistent with the full summer 2006 results presented in Glotfelty et al. (2019).

These findings have significant implications for the study of ACI within regional coupled-meteorology-chemistry models (RCMCMs), general circulation models (GCMs) and Earth system models (EaSMs). RCMCMs, GCMs, and EaSMs typically do not treat subgrid-scale microphysics and thus are not truly representing the impacts of ACI on strongly convective regions dominated by subgrid-scale clouds, such as the tropics or the Southeast United States. Further, GCMs/EaSMs are often configured with large horizontal grid spacing (e.g., $1.0^{\circ}$ latitude $\times 1.0^{\circ}$ longitude) leading to an overestimation of aerosol impacts on autoconversion. RCMCMs are also 

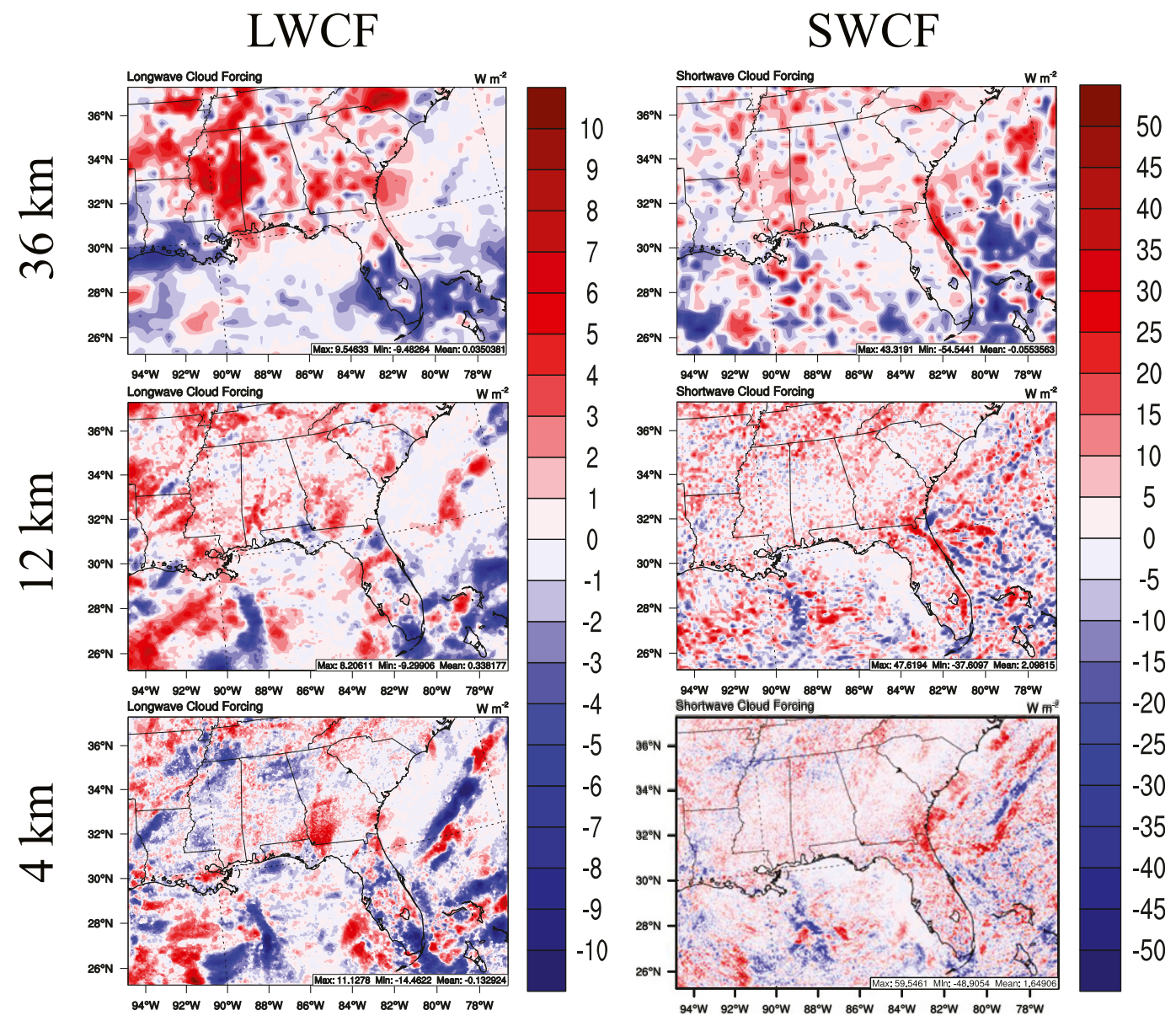

FIG. 15. The difference in (left) longwave cloud forcing and (right) shortwave cloud forcing between the WACI and LAERO simulations over the SE region at (top) 36 , (middle) 12 , and (bottom) $4 \mathrm{~km}$.

typically configured at mesoscale grid spacing (i.e., 36 and $12 \mathrm{~km}$ ), and thus these models are not simulating the moisture competition effects of ACI between grid-scale and subgridscale clouds. This work also highlights deficiencies in WRF regarding the interactions between grid-scale and subgrid-scale clouds. These deficiencies indicate that the order in which physics parameterizations are solved and the importance of advecting subgrid-scale hydrometeors may need further development to improve the representation of grid-scale and subgrid-scale ACI processes.

Overall, the WRF-ACI system has shown significant sensitivity of ACI by simulating ACI within the so-called gray zone or convection-permitting scales. Generally, these results show that changing the grid spacing within the model alters the types of clouds the model produces as well as the microphysical processes within clouds. These differences in cloud type and cloud microphysics lead to differing impacts on ACI that may be especially important in regions of complex terrain or regions with mixed-phase clouds. As mentioned in Glotfelty et al. (2019), the main limiting factors of the WRF-ACI system are the manner in which grid-scale and subgrid-scale clouds are represented. Additionally, the work of Ancell et al. (2018) demonstrates that sensitivity simulation studies, like those shown here, are susceptible to "chaos seeding" from numerical artifacts and more work must be done to try and disentangle these unrealistic numerical perturbations from realistic changes. More development of these processes is required by the scientific community in order to determine how much of the simulated ACI impacts result from model framework limitations verses how much of these impacts are physically based. Future studies should also focus on incorporating subgrid-scale microphysics parameterizations, thermodynamic invigoration effects, and aerosol impacts on cloud ice into RCMCMs and GCMs/EaSMs to determine if the use of prognostic aerosols changes the results significantly from those in this study. Finally, WRF-ACI studies in more locations and for longer time periods will also be required in the future to illuminate the impacts of ACI in different environments.

Acknowledgments. Thanks are due to Dr. Yang Zhang of North Carolina State University for providing the aerosol data for the CESM-NCSU aerosol climatology. The authors thank Dr. Patrick Campbell currently at NOAA for valuable scientific discussions related to this work. Authors thank EPA's internal reviewers, Drs. Chris Weaver and Brett Gantt for providing us with valuable comments on this work. Authors 
also thank Ms. Rachel Porter for her technical edits improving the readability of the text. This document has been reviewed by the U.S. Environmental Protection Agency, Office of Research and Development, and approved for publication. The views expressed and the contents are solely the responsibility of the authors, and do not necessarily represent the official views of the U.S. EPA.

Data availability statement. All data used to generate figures and tables shown in this article can be freely downloaded at https://edg.epa.gov/metadata/catalog/main/home.page.

\section{REFERENCES}

Abdul-Razzak, H., and S. J. Ghan, 2000: A parameterization of aerosol activation: 2. Multiple aerosol types. J. Geophys. Res., 105, 6837-6844, https://doi.org/10.1029/1999JD901161.

Alapaty, K., D. Niyogi, F. Chen, P. Pyle, A. Chandrasekar, and N. Seaman, 2008: Development of the flux-adjusting surface data assimilation system for mesoscale models. J. Appl. Meteor. Climatol., 47, 2331-2350, https://doi.org/10.1175/ 2008JAMC1831.1.

— J. S. Kain, J. S. Herwehe, O. R. Bullock, M. S. Mallard, T. L. Spero, and C. G. Nolte, 2014: Multiscale Kain-Fritsch scheme: Formulations and tests. 13th Annual CMAS Conf., Chapel Hill, NC, CMAS.

Albrecht, B. A., 1989: Aerosols, cloud microphysics, and fractional cloudiness. Science, 245, 1227-1230, https://doi.org/ 10.1126/science.245.4923.1227.

Ancell, B. C., A. Bogusz, M. J. Lauridsen, and C. J. Nauert, 2018: Seeding chaos: The dire consequences of numerical noise in NWP perturbation experiments. Bull. Amer. Meteor. Soc., 99, 615-628, https://doi.org/10.1175/BAMS-D-17-0129.1.

Archer-Nicholls, S., D. Lowe, D. M. Schultz, and G. McFiggans, 2016: Aerosol-radiation-cloud interactions in a regional coupled model: The effects of convective parameterization and resolution. Atmos. Chem. Phys., 16, 5573-5594, https:// doi.org/10.5194/acp-16-5573-2016.

Bergeron, T., 1935: On the physics of clouds and precipitation. Proces Verbaux de l'Association de Météorologie, Lisbon, Portugal, International Union of Geodesy and Geophysics, 156-178.

Boucher, O., and Coauthors, 2013: Clouds and aerosols. Climate Change 2013: The Physical Science Basis, T. F. Stocker et al., Eds., Cambridge University Press, 571-657.

Bullock, O. R., K. Alapaty, J. A. Herwehe, M. S. Mallard, T. L. Otte, R. C. Gilliam, and C. G. Nolte, 2014: An observationbased investigation of nudging in WRF for downscaling surface climate information to $12-\mathrm{km}$ grid spacing. J. Appl. Meteor. Climatol., 53, 20-33, https://doi.org/10.1175/JAMCD-13-030.1.

Chen, F., and J. Dudhia, 2001: Coupling an advanced landsurface/hydrology model with the Penn State/US7 MM5 modeling system. Part I: Model implementation and sensitivity. Mon. Wea. Rev., 129, 569-585, https://doi.org/10.1175/ 1520-0493(2001)129<0569:CAALSH > 2.0.CO;2.

Chen, G., W.-C. Wang, and J.-P. Chen, 2015: Aerosol-stratocumulusradiation interactions over southeast Pacific. J. Atmos. Sci., 72 , 2612-2621, https://doi.org/10.1175/JAS-D-14-0319.1.

Clough, S. A., M. W. Shephard, J. E. Mlawer, J. S. Delamere, M. J. Iacono, K. Cady-Pereira, S. Boukabara, and P. D. Brown, 2005: Atmospheric radiative transfer modeling: A summary of the AER codes. J. Quant. Spectrosc. Radiat. Transfer, 91, 233-244, https://doi.org/10.1016/j.jqsrt.2004.05.058.

Cooper, W. A., 1986: Ice initiation in natural clouds. Precipitation Enhancement-A Scientific Challenge, Meteor. Monogr., No. 21, Amer. Meteor. Soc., 29-32, https://doi.org/10.1175/00659401-21.43.1.

Denman, K. Y., and Coauthors, 2007: Coupling between changes in the climate system and biogeochemistry. Climate Change 2007: The Physical Science Basis, S. Solomon et al., Eds., Cambridge University Press, 499-587.

Ek, M. B., K. E. Mitchell, Y. Lin, E. Rogers, P. Grunmann, V. Koren, G. Gayno, and J. D. Tarpley, 2003: Implementation of Noah land surface model advances in the National Centers for Environmental Prediction operational mesoscale Eta model. J. Geophys. Res., 108, 8851, https://doi.org/10.1029/ 2002JD003296,D22.

Fan, J., Y. Wang, D. Rosenfeld, and X. Liu, 2016: Review of aerosol-cloud interactions: Mechanisms, significance, and challenges. J. Atmos. Sci., 73, 4221-4252, https://doi.org/ 10.1175/JAS-D-16-0037.1.

Findeisen, W., 1938: Kolloid-meteorologische Vorgänge bei Neiderschlags-bildung. Meteor. Z., 55, 121-133.

Ghan, S., and Coauthors, 2016: Challenges in constraining anthropogenic aerosol effects on cloud radiative forcing using presentday spatiotemporal variability. Proc. Natl. Acad. Sci. USA, 113, 5804-5811, https://doi.org/10.1073/pnas.1514036113.

Glotfelty, T., J. He, and Y. Zhang, 2017: The impact of future climate policy scenarios on air quality and aerosol/cloud interactions using an advanced version of CESM/CAM5: Part I. Model evaluation for the current decadal simulations. Atmos. Environ., 152, 222-239, https://doi.org/10.1016/ j.atmosenv.2016.12.035.

_- K. K. Alapaty, J. He, P. Hawbecker, X. Song, and G. Zhang, 2019: The Weather Research and Forecasting Model with Aerosol-Cloud Interactions (WRF-ACI): Development, evaluation, and initial application. Mon. Wea. Rev., 147, 1491-1511, https://doi.org/10.1175/MWR-D-18-0267.1.

He, J., and K. Alapaty, 2018: Precipitation partitioning in multiscale atmospheric simulations: Impacts of stability restoration methods. J. Geophys. Res. Atmos., 123, $10185-10201$, https:// doi.org/10.1029/2018JD028710.

_ , T. Glotfelty, K. Yahya, K. Alapaty, and S. Yu, 2017: Does temperature nudging overwhelm aerosol radiative effects in regional integrated climate models? Atmos. Environ., 154, 42-52, https://doi.org/10.1016/j.atmosenv.2017.01.040.

Hong, S.-Y., and J. Dudhia, 2012: Next-generation numerical weather prediction: Bridging parameterization, explicit clouds, and large eddies. Bull. Amer. Meteor. Soc., 93 (1), ES6-ES9, https://doi.org/10.1175/2011BAMS3224.1.

_-, Y. Noh, and J. Dudhia, 2006: A new vertical diffusion package with an explicit treatment of entrainment processes. Mon. Wea. Rev., 134, 2318-2341, https://doi.org/10.1175/ MWR3199.1.

Hu, Y., S. Rodier, K. Xu, W. Sun, J. Huang, B. Lin, P. Zhai, and D. Josset, 2010: Occurrence, liquid water content, and fraction of supercooled water clouds from combined CALIOP/IIR/MODIS measurements. J. Geophys. Res., 115, D00H34, https://doi.org/ 10.1029/2009JD012384.

Iacono, M. J., J. S. Delamere, E. J. Mlawer, M. W. Shephard, S. A. Clough, and W. D. Collins, 2008: Radiative forcing by longlived greenhouse gases: Calculations with the AER radiative transfer models. J. Geophys. Res., 113, D13103, https://doi.org/ 10.1029/2008JD009944. 
Igel, A. L., S. C. van den Heever, C. M. Naud, S. M. Saleeby, and D. J. Posselt, 2013: Sensitivity of warm-frontal processes to cloud-nucleating aerosol concentrations. J. Atmos. Sci., 70, 1768-1783, https://doi.org/10.1175/JAS-D-12-0170.1.

Janjić, Z. I., 2002: Nonsingular implementation of the MellorYamada level 2.5 scheme in the NCEP Meso Model. NCEP Office Note 437, $61 \mathrm{pp}$.

Jones, A., D. L. Roberts, M. J. Woodage, and C. E. Johnson, 2001: Indirect sulphate aerosol forcing in a climate model with an interactive sulphur cycle. J. Geophys. Res., 106, 20 293-20310, https://doi.org/10.1029/2000JD000089.

Khairoutdinov, M., and Y. Kogan, 2000: A new cloud physics parameterization in a large-eddy simulation model of marine stratocumulus. Mon. Wea. Rev., 128, 229-243, https://doi.org/ 10.1175/1520-0493(2000)128<0229:ANCPPI > 2.0.CO;2.

Kogan, Y., 2013: A cumulus cloud microphysics parametrization for cloud-resolving models. J. Atmos. Sci., 70, 1423-1436, https://doi.org/10.1175/JAS-D-12-0183.1.

Kushta, J., G. Kallos, M. Astitha, S. Solomos, C. Spyrou, C. Mitsakou, and J. Lelieveld, 2014: Impact of natural aerosols on atmospheric radiation and consequent feedbacks with the meteorological and photochemical state of the atmosphere. J. Geophys. Res. Atmos., 119, 1463-1491, https:// doi.org/10.1002/2013JD020714.

Li, L., W. Li, and J. Jin, 2014: Improvements in WRF simulation skills of southeastern United States summer rainfall: Physical parameterization and horizontal resolution. Climate Dyn., 43, 2077-2091, https://doi.org/10.1007/s00382-013-2031-2.

Liu, X. H., and J. E. Penner, 2005: Ice nucleation parameterization for global models. Meteor. Z., 14, 499-514, https://doi.org/ 10.1127/0941-2948/2005/0059.

Ma, P.-L., and Coauthors, 2015: How does increasing horizontal resolution in a global climate model improve the simulation of aerosol-cloud interactions? Geophys. Res. Lett., 42, 5058-5065, https://doi.org/10.1002/2015GL064183.

Mahoney, K. M., 2016: The representation of cumulus convection in high-resolution simulations of the 2013 Colorado Front Range flood. Mon. Wea. Rev., 144, 4265-4278, https://doi.org/ 10.1175/MWR-D-16-0211.1.

Mass, C., D. Ovens, K. Westrick, and B. A. Colle, 2002: Does increasing horizontal resolution produce more skillful forecasts? Bull. Amer. Meteor. Soc., 83, 407-430, https://doi.org/10.1175/ 1520-0477(2002)083<0407:DIHRPM>2.3.CO;2.

Menon, S., and L. Rotstayn, 2006: The radiative influence of aerosol effects on liquid-phase cumulus and stratiform clouds based on sensitivity studies with two climate models. Climate Dyn., 27, 345-356, https://doi.org/10.1007/s00382-006-0139-3.

Monin, A. S., and A. M. Obukhov, 1954: Basic laws of turbulent mixing in the surface layer of the atmosphere (in Russian). Contrib. Geophys. Inst. Acad. Sci. USSR, 151, 163-187.

Morrison, H., J. A. Curry, and V. I. Khvorostyanov, 2005: A new double-moment microphysics parameterization for application in cloud and climate models. Part I: Description. J. Atmos. Sci., 62, 1665-1677, https://doi.org/10.1175/JAS3446.1.

— , G. Thompson, V. Tatarskii, 2009: Impact of cloud microphysics on the development of trailing stratiform precipitation in a simulated squall line: Comparison of one- and twomoment schemes. Mon. Wea. Rev., 137, 991-1007, https:// doi.org/10.1175/2008MWR2556.1.

Nelson, B. R., O. P. Prat, D.-J. Seo, and E. Habib, 2016: Assessment and implications of NCEP stage IV quantitative precipitation estimates for product intercomparisons. Wea. Forecasting, 31, 371-394, https://doi.org/10.1175/WAF-D-14-00112.1.
Penner, J. E., and Coauthors, 2006: Model intercomparison of indirect aerosol indirect effects. Atmos. Chem. Phys., 6, 3391-3405, https://doi.org/10.5194/acp-6-3391-2006.

Possner, A., E. M. Zubler, U. Lohmann, and C. Schär, 2016: The resolution dependence of cloud effects and ship-induced aerosolcloud interactions in marine stratocumulus. J. Geophys. Res. Atmos., 121, 4810-4829, https://doi.org/10.1002/2015JD024685.

Quaas, J., and Coauthors, 2009: Aerosol indirect effects-General circulation model intercomparison and evaluation with satellite data. Atmos. Chem. Phys., 9, 8697-8717, https://doi.org/ 10.5194/acp-9-8697-2009.

Rosenfeld, D., U. Lohmann, G. B. Raga, C. D. O’Dowd, M. Kulmala, S. Fuzzi, A. Reissell, and M. O. Andreae, 2008: Flood or drought: How do aerosols affect precipitation? Science, 321, 1309-1313, https://doi.org/10.1126/science.1160606.

Saleeby, S. M., and S. C. van den Heever, 2013: Developments in the CSU-RAMS aerosol model: Emissions, nucleation, regeneration, deposition, and radiation. J. Appl. Meteor. Climatol., 52, 2601-2622, https://doi.org/10.1175/JAMC-D-12-0312.1.

Skamarock, W. C., and J. B. Klemp, 2008: A time-split nonhydrostatic atmospheric model for Weather Research and Forecasting applications. J. Comput. Phys., 227, 3465-3485, https://doi.org/10.1016/j.jcp.2007.01.037.

Song, X., and G. J. Zhang, 2011: Microphysics parameterization for convective clouds in a global climate model: Description and single-column model tests. J. Geophys. Res., 116, D02201, https://doi.org/10.1029/2010JD014833.

Stauffer, D. R., and N. L. Seaman, 1990: Use of four-dimensional data assimilation in a limited-area model. Part I: Experiments with synoptic scale data. Mon. Wea. Rev., 118, 1250-1277, https://doi.org/10.1175/1520-0493(1990)118<1250:UOFDDA > 2.0.CO;2.

_ tion. J. Appl. Meteor., 33, 416-434, https://doi.org/10.1175/ 1520-0450(1994)033<0416:MFDDA > 2.0.CO;2.

Storer, R., S. C. van den Heever, and G. L. Stephens, 2010: Modeling aerosol impacts on convective storms in different environments. J. Atmos. Sci., 67, 3904-3915, https://doi.org/ 10.1175/2010JAS3363.1.

Thompson, G., and T. Eidhammer, 2014: A study of aerosol impacts on clouds and precipitation development in a large winter cyclone. J. Atmos. Sci., 71, 3636-3658, https://doi.org/ 10.1175/JAS-D-13-0305.1.

Tonttila, J., H. Jarvinen, and P. Raisanen, 2015: Explicit representation of subgrid variability in cloud microphysics yields weaker aerosol indirect effect in the ECHAM5-HAM2 climate model. Atmos. Chem. Phys., 15, 703-714, https://doi.org/ 10.5194/acp-15-703-2015.

Wall, C., E. Zipser, and C. Liu, 2013: A investigation of the aerosol indirect effect on convective intensity using satellite observations. J. Atmos. Sci., 71, 430-447, https://doi.org/ 10.1175/JAS-D-13-0158.1.

Wegener, A., 1911: Thermodynamik der Atmosphäre. J. A. Barth, $331 \mathrm{pp}$.

White, B., E. Gryspeerdt, P. Stier, H. Morrison, G. Thompson, and Z. Kipling, 2017: Uncertainty from the choice of microphysics scheme in convection-permitting models significantly exceeds aerosol effects. Atmos. Chem. Phys., 17, 12 145-12 175, https:// doi.org/10.5194/acp-17-12145-2017.

Wilcox, L. J., E. J. Highwood, B. B. B. Booth, and K. S. Carslaw, 2015: Quantifying sources of inter-model diversity in the cloud albedo effect. Geophys. Res. Lett., 42, 1568-1575, https:// doi.org/10.1002/2015GL063301. 
Wyant, M. C., and Coauthors, 2015: Global and regional modeling of clouds and aerosols in the marine boundary layer during VOCALS: the VOCA intercomparison. Atmos. Chem. Phys., 15, 153-172, https://doi.org/10.5194/ acp-15-153-2015.

Xie, X., and X. Liu, 2015: Aerosol-cloud-precipitation interactions in WRF Model: Sensitivity to autoconversion parameterization. J. Meteor. Res., 29, 72-81, https://doi.org/ 10.1007/s13351-014-4065-8.
Zelinka, M. D., T. Andrews, P. M. Forster, and K. E. Taylor, 2014: Quantifying components of aerosol-cloud-radiation interactions in climate models. J. Geophys. Res. Atmos., 119, 7599-7615, https://doi.org/10.1002/2014JD021710.

Zheng, Y., K. Alapaty, J. S. Herwehe, A. Del Genio, and D. Niyogi, 2016: Improving high-resolution weather forecasts using the Weather Research and Forecasting (WRF) Model with an updated Kain-Fritsch scheme. Mon. Wea. Rev., 144, 833-860, https://doi.org/10.1175/MWR-D-15-0005.1. 